\title{
Segregación residencial y movilidad cotidiana en el contexto metropolitano. Un estudio a partir de las relaciones Bogotá-Soacha*
}

Residential Segregation and Daily Mobility in the Metropolitan Context. A Case Study Based on the Relations between Bogotá and Soacha

Segregação residencial e mobilidade cotidiana no contexto metropolitano. Um estudo a partir das relações Bogotá-Soacha

\author{
Carlos Augusto Moreno Luna ${ }^{* *}$ \\ Melba Rubiano Bríñez ${ }^{* \star}$
}

Recibido: 29 de mayo de 2014

Aprobado: 18 de julio de 2014

Doi: dx.doi.org/10.12804/territ31.2014.06

\section{Para citar este artículo:}

Moreno Luna, C. A., \& Rubiano Bríñez, M. (2014). Segregación residencial y movilidad cotidiana en el contexto metropolitano. Un estudio a partir de las relaciones Bogotá-Soacha. Territorios, (31), 133-162. Doi: dx.doi. org/10.12804/territ31.2014.06

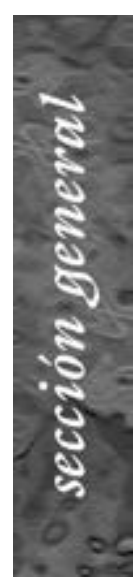

* Esta investigación contó con el apoyo y colaboración del profesor Álvaro Mauricio Torres.

* Magister en Urbanismo y Ordenamiento Territorial de la Universidad Lumière Lyon II - Instituto de Urbanismo de Lyon (Francia). Investigador/docente de la Maestria en Gestión Urbana de la Universidad Piloto de Colombia, Línea Hábitat, Ambiente y Territorio. Correos electrónicos: carlosmoreno1@unipiloto.edu.co, camoluna@yahoo.fr

*** Magister en Gestión Urbana y Regional, Instituto de Pesquisa e Planejamento Urbano Regional de la Universidad Federal de Rio de Janeiro (IPPURUFRJ). Investigadora/docente de la Maestría en Gestión Urbana de la Universidad Piloto de Colombia. $\Rightarrow$ 
Palabras clave

Segregación residencial, movilidad, Ciudad Verde, metropolización.

Keywords

Residential segregation, mobility, Green City, metropolization.

Palavras-chave

Segregação residencial, mobilidade, Cidade Verde, metropolização.

\section{territarias 31}

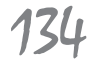

\section{RESUMEN}

El artículo presenta algunos resultados y reflexiones preliminares generados en torno a la investigación que se lleva a cabo desde la Maestría en Gestión Urbana de la Universidad Piloto de Colombia acerca de las relaciones de metropolización entre Bogotá y Soacha bajo el fenómeno de segregación residencial y la movilidad cotidiana. Específicamente, se hace un análisis a partir de las implicaciones generadas por el macroproyecto Ciudad Verde y, en este sentido, se estudia si la ejecución de este tiene repercusiones e implicaciones en la población residente en dicho proyecto. La temática lleva a plantear el siguiente cuestionamiento: ¿el desarrollo de un macroproyecto de vivienda como Ciudad Verde será (o no) generador de segregación residencial?

En ese sentido, los resultados describen algunos de los hallazgos relevantes y sugieren que las condiciones de movilidad presentan un deterioro agravado por el impacto sobre el reducido presupuesto familiar, lo que implica un sobrecosto debido a la necesidad de recurrir a más de un medio de transporte para la movilización, así como a mayores tiempos de desplazamiento.

\section{ABSTRACT}

The paper shows some preliminary results and reflections generated in the research that is carry out in the Master in Urban Management at Piloto University of Colombia, it is about the metropolitan relationships between Bogotá and Soacha, under the residential segregation phenomenon and daily population mobility; specifically it discusses the implications generated by the macro-project 'Ciudad Verde' (Green City), in this sense, it studies if the project execution has repercussions and implications for their inhabitants. The discussion leads to the next question: Whether the development of a housing macro-project as Green City would generate residential segregation?

In that sense, the results describe some relevant findings and suggest that in terms of mobility conditions, there is a serious deterioration due to the impact in the reduced family budget, which implies an over cost due to the need of using more than one transportation mean, as well as higher travel time.

\section{Resumo}

$\mathrm{O}$ artigo apresenta alguns resultados e reflexões preliminares gerados em torno à pesquisa que levou-se a cabo desde o Mestrado em Gestão Urbana da Universidad Piloto de Colombia acerca das relações de metropolização entre Bogotá e Soacha sob o fenômeno de segregação residencial e a mobilidade cotidiana. Especificamente, se faz uma análise a partir das implicações geradas pelo macroprojeto Cidade Verde e, neste sentido, estuda-se se a execução deste tem repercussões e implicações na população residente em dita área. A temática leva a plantear o seguinte questionamento: o desenvolvimento de um macroprojeto de moradia como Cidade Verde será (ou não) gerador de segregação residencial?

Neste sentido, os resultados descrevem alguns dos achados relevantes e sugerem que as condições de mobilidade apresentam uma deterioração agravada pelo impacto sobre o pressuposto familiar reduzido, o que implica um sobrecusto devido à necessidade de recorrer a mais de um meio de transporte para mobilização, assim como a maiores tempos de deslocamento. 


\section{Introducción}

Los desequilibrios regionales que están presentes en la gran mayoría de áreas metropolitanas de las ciudades de América Latina, los cuales han sido investigados por varios autores (Sabatini, Alfonso, Dureau, entre otros), ponen de manifiesto la necesidad de abordar el estudio de las implicaciones relacionadas con la metropolización para entender que, si bien desde hace muchos años se habla de los impactos del crecimiento urbano acelerado, hasta hace poco la gestión urbana podía ser manejada desde lo municipal. Hoy en día, lo urbano ya no corresponde solamente a los límites de las jurisdicciones locales, lo que implica que es necesario idear mecanismos para gestionar asuntos metropolitanos, como servicios públicos, servicios ambientales, vivienda y transporte.

En la literatura, se vislumbra que, en estos procesos de metropolización (manifestados tanto en el crecimiento espacial y demográfico como en las interacciones entre un núcleo y uno o varios municipios metropolizados), no solo se ponen a prueba las formas institucionales de gobierno, sino que tienen también profundos impactos en la composición social del espacio, creando nuevas formas de exclusión. Las antiguas periferias pasan a ser lugares centrales, la población más pobre termina desplazada a nuevas fronteras y periferias con graves deficiencias de localización e infraestructura.

En varias ciudades de Latinoamérica, se empieza a dar un proceso donde se verifica la presencia de una estructura metropolitana polarizada y segregada con una diferencia entre los distintos grupos económicos de la ciudad (Jirón, Lange \& Bertrand, 2010). Para el caso concreto de Bogotá, esta estructura se comienza a dar desde finales del siglo XIX cuando la población más adinerada empieza a salir del centro de la ciudad hacia el norte en búsqueda de mayores extensiones de tierra y lugares más 'campestres', lo que lleva a la creación de un nuevo centro suburbano, el cual, gracias a la extensión de la línea del tranvía, seguía conectado con el centro de la ciudad, lugar donde se lleva a cabo la mayor actividad política, económica y financiera. Para esta época, la ciudad contaba con alrededor de 85.000 habitantes y la mayoría de esta población se ubicaba en el casco central muy compacto con un diámetro de tan solo $4 \mathrm{~km}$. Este núcleo suburbano estaba ubicado a $6 \mathrm{~km}$ de dicho casco (Jaramillo \& Parias, 1995).

La estructura metropolitana polarizada y segregada, como es llamada por Jiron, Lange \& Bertrand (2010), se acentúa aún más en Bogotá entre 1940 y 1970 cuando el centro tradicional empieza a ser abandonado por las clases altas en búsqueda de lugares ubicados en el norte de la ciudad, en localizaciones más septentrionales al pie de los cerros orientales, y, por otro lado, el sur acentúa su característica popular, mientras que la naciente industria se localiza en el occidente, en cercanía a la Estación del Ferrocarril (Dureau, Barbary \& Lulle, 2007). Esta forma de crecimiento de la ciudad se sigue dando en las siguientes y Territorio. Correos electrónicos: melba-rubiano@ unipiloto.edu.co, melbarubiano@gmail.com territarios 31

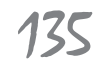


décadas; las clases más adineradas siguen el desplazamiento progresivo hacia el norte, mientras que las familias más pobres siguen alejándose cada vez más hacia el sur (Dureau, 2002).

Un buen número de hogares pobres salió del centro de la ciudad buscando lugares más económicos dónde vivir, por lo general, a lugares ubicados en la periferia. Esta forma segmentada de organización de la ciudad genera una fuerte heterogeneidad en la ocupación del espacio metropolitano (Dureau, Barbary \& Lulle, 2007), por lo tanto, las capacidades de ubicación y movilidad se convirtieron en un factor fundamental de la integración social y un multiplicador de las desigualdades de ingreso (Garretón, 2012).

En consideración a la metropolización, en el ámbito nacional y local, se viene dando desde mediados del siglo XX (década de 1950) un incremento en los movimientos migratorios hacia las ciudades de mayor desarrollo económico y social. En la década de 1960, "prevalecían el crecimiento demográfico acelerado, la industrialización, las migraciones rural-urbanas, que privilegiaron a cuatro ciudades" (Murad, 2003, p. 7), $\mathrm{y}$, por otro lado, "la municipalización y la privatización que determinaban el sistema de planeación y gestión territorial, sistema útil para la prestación de servicios básicos o la atención de un modelo de desarrollo inmobiliario, pero insuficiente para responder a fenómenos territoriales contemporáneos como la metropolización y las crecientes demandas de movilidad poblacional" (Hurtado, Torres \& Miranda, 2011, p. 98).
Después de la década de 1970, el proceso de crecimiento demográfico y la disminución de la intensidad de los flujos migratorios son la constante. El frente de la urbanización pasa a los límites de la capital, lo que progresivamente genera un nuevo modelo de desarrollo metropolitano ( $\mathrm{Du}-$ reau, 2002) en donde, como se mencionó anteriormente, el norte se distingue por la migración de las clases adineradas y el sur por las clases más populares y pobres. Como lo menciona Cortés (1993), "Soacha [municipio ubicado al sur de Bogotá] se ha convertido en un importante receptor de la subnormalidad (de la capital) que ya no se localiza dentro del perímetro del Distrito, supliendo en cierta forma el agotamiento de tierra urbanizable en la ciudad y aprovechando su cercanía con ella" (en Dureau, 2002, p. 165). Este proceso ha generado que el esquema de segregación residencial y la estructuración funcional hayan sobrepasado los límites de la ciudad (Dureau, 2002), y, al mismo tiempo, se hayan convertido en un problema metropolitano (figura 1).

Pero, ¿qué se entiende por segregación? De acuerdo con Castells (1974, p. 204), se entiende la segregación "como la tendencia a la organización del espacio en zonas de fuerte homogeneidad social interna y de fuerte disparidad social entre ellas, entendiéndose esta disparidad no solo en términos de diferencia, sino de jerarquía". Este significado se acerca bastante a la realidad que viven hoy en día nuestras ciudades latinoamericanas.

La noción de segregación residencial es abordada por Sabatini, Cáceres y Cerda 


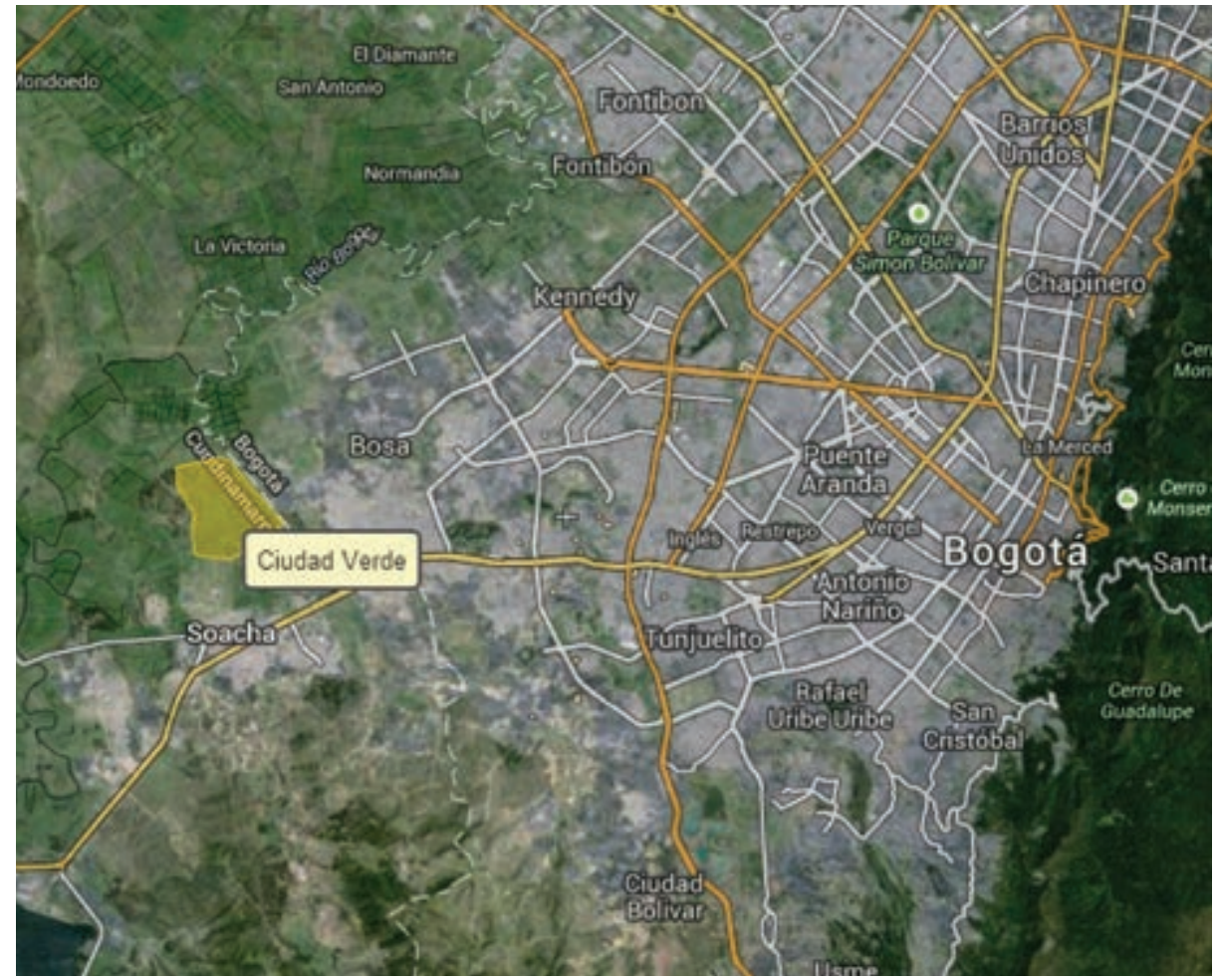

Fuente: www.wikimapia.org

(2001, p. 23) como "desigualdades sociales, exclusión social e incluso pobreza". De manera similar, Sabatini et al. (2001, p. 30) la definen como "aquella disposición espacial aglomerada de un grupo social que contribuye a agravar determinados problemas para sus integrantes". Sin embargo, dentro de este mismo trabajo de investigación, se asigna otra definición para la segregación residencial. Esta definición es planteada en términos operacionales, es decir, en el sentido de analizar la segrega- ción residencial como variable de estudio en relación con los problemas sociales que los autores en mención identifican: desempleo, movilidad urbana y retraso escolar.

Tales circunstancias también son expresadas por Rodríguez (2001), quien identifica la segregación residencial como la existencia de diferencias o desigualdades dentro de un colectivo y la tipificación de los sujetos en categorías que separan a los individuos desde el punto de vista geográfico, y la existencia de diferencias en ciertas territarias 31 
características que se verifican entre los residentes de las distintas zonas de una ciudad.

Lévy y Brun (2002, p. 147) dan un significado que se cree puede contextualizar mejor la situación sobre la segregación: "Designan una serie de fenómenos complejos, variables y compuestos, pero que implican siempre formas de desigual distribución de grupos de población en el espacio, formas consideradas como reveladoras pero también - y es allí donde reside la principal ambigüedad de la nocióncomo factores de patologías tanto sociales como espaciales".

Arriagada y Rodríguez (2003) plantean que la definición frecuente sobre este concepto posee varias falencias, entre ellas que la segregación residencial está más ligada a un distanciamiento sociocultural y no solamente físico, es decir que la cercanía geográfica no garantiza intercambio ni asegura afinidad o armonía entre los distintos grupos sociales; más aún, la proximidad geográfica puede agudizar el enfrentamiento entre grupos (p. 10). Adicional a esto, sostienen los autores que el espacio residencial no es el único lugar donde los diversos grupos sociales pueden interactuar (escuela, mercado, trabajo, etc.), lo que significa que la segregación residencial no implica necesariamente falta o ausencia de integración entre los grupos sociales.

En este sentido, la distancia física que separa los proyectos de vivienda de interés social en varias de las ciudades latinoamericanas que se ubican principalmente en las periferias de la ciudad, en donde el precio del suelo es más barato, y lejos de donde se "concentra el empleo, la recreación, los servicios, entre otras actividades, convierte a la movilidad cotidiana urbana en un factor relevante de análisis y discusión para la comprensión [...] de la calidad de vida de la población" como señalan Jirón, Lange y Bertrand (2010).

Los planteamientos anteriormente expresados permiten llevar a pensar que, en la mayoría de las ciudades latinoamericanas, no ha habido una verdadera planificación urbana. Es decir, una planificación en la cual se permita que los nuevos desarrollos, en especial los proyectos dirigidos a la población de bajos ingresos, se ubiquen en áreas periféricas en donde por lo general los servicios públicos, de transporte, salud, educación, son muy precarios o inexistentes. La falta de acceso a estos servicios se constituye en un factor de exclusión social que afecta en especial a la población ubicada en las periferias, causando que el círculo vicioso de la pobreza se repita (Lizarraga, 2012). Esta población tiene una precaria accesibilidad a los principales bienes por su modelo territorial y modelo de movilidad, los cuales son necesarios de entender contextualizados dentro de un territorio, lo que implica algunas condiciones que no pueden "darse por establecidas, y que constituyen un atributo que no se distribuye de forma equitativa entre las personas" (Hernández, 2012).

Siendo así, es importante comprender el territorio en el que se está llevando a cabo cualquier tipo de intervención, para descubrir sus condiciones particulares, en este caso, aquellas que tienen que ver con 
el transporte. Si bien la evolución de los sistemas de transporte y de la planificación urbana ha influido en las dinámicas de movilidad de los ciudadanos, se hace mucho más compleja la identificación del papel del transporte dentro de la urbanización (Montezuma, 1999, en Avellaneda, 2007), y, además, el hecho de analizar solamente la desigualdad y la exclusión social desde la segregación residencial omite un tema primordial que tiene que ver con la forma en que diariamente se desplazan estas personas para desarrollar sus actividades diarias (Jirón, Lange \& Bertrand, 2010).

Es así que la movilidad cotidiana juega un papel muy importante en los procesos de segregación residencial. Son, principalmente, los ciudadanos que residen en la periferia de la ciudad los que encuentran dificultad para poder conseguir un medio de transporte eficiente y económico, debido a que, en estas áreas deprimidas de la ciudad, las vías de acceso están en un alto grado de deterioro, $y$, en muchos otros casos, ni siquiera existen vías de acceso aptas para vehículos. Además, las largas distancias que buena parte de las personas en situación de pobreza deben recorrer en la mayor parte de las ciudades latinoamericanas, debido a la distancia que separa sus lugares de residencia de los centros de actividad económica, hacen que un porcentaje nada despreciable de dichos desplazamientos requieran de uno o más transbordos (Avellaneda, 2007, p. 149). Como lo mencionan Lévy \& Dureau (2002), citados en Salas (2008), esta movilidad de las personas se ha empezado a considerar como una variable de aproximación a la segregación.

La restricción económica en muchos casos es un impedimento para movilizarse y llevar a cabo actividades diarias, como el trabajo y la educación; de esta forma, los desplazamientos de las personas que residen lejos de la llamada 'ciudad central' ven restringidos sus viajes a lo estrictamente necesario, sacrificando muchas veces su escaso ingreso. Según Fox (citado en Avellaneda, 2007), las posibilidades de desplazamiento de los ciudadanos están en estrecha relación con las posibilidades de uso de los distintos medios de transporte. Es así como "los sistemas de transporte colectivo se constituyen en catalizadores de las penurias de la inmensa mayoría de los trabajadores, estudiantes y viajeros ocasionales que no disponen de modos privados a su alcance para realizar prolongados trayectos cotidianos" (Alfonso, 2012, p. 326). Estas áreas deprimidas y de bajos ingresos (formales e informales) que se ubican en las zonas periféricas de la ciudad, en la mayoría de los casos, carecen de un medio de transporte público digno, y menos aún uno privado, lo que acentúa la penuria y la privación de muchos servicios y actividades que brinda la ciudad.

Los escasos estudios efectuados en América Latina muestran que los desplazamientos diarios de las personas residentes en las periferias de las ciudades se están realizando en espacios cercanos, mejorando la calidad de vida de estas personas, ya que no necesitan desplazarse largas distancias para llegar a su lugar de trabajo (Dureau territarias 31

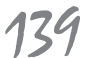


\& Goüeset, 2012), pero esto es algo que necesita ser comprobado con mayores estudios. La movilidad cotidiana tiene una relación directa con la pobreza, entre más pobre sea la persona, mayores problemas y dificultades tendrá para desplazarse, debido, entre otras razones, a la mala y escasa oferta de un transporte público eficiente y rápido, así como por la segregación de sus hogares hacia la periferia de la ciudad, haciendo los viajes diarios mucho más largos en cuanto a distancia. Existe una relación entre pobreza y movilidad diaria que compromete un tema de investigación emergente. Varios investigadores han demostrado que las desigualdades sociales inducen a desigualdades en movilidad (Vasconcellos, 1996; Figueroa, 2005; en Dureau \& Goüeset, 2012).

La distancia entre los lugares de trabajo, las residencias y los centros educativos, se convierte en una barrera para muchos trabajadores y estudiantes. Un gran número de personas no tiene los medios económicos para ir de un lado a otro de la ciudad, porque, en muchos casos, representarían costos adicionales. Por lo tanto, como expresa la Comisión Económica para América Latina y el Caribe (Cepal) (2012), algunos estudios exponen que la inserción de los trabajadores, especialmente de aquellos que residen en barrios apartados, no solo debido a la distancia entre el lugar de trabajo y su hogar, sino también por la naturaleza desfavorable de las condiciones laborales en relación con las de los vecindarios más pudientes, en el mercado laboral ha sido
Así mismo, mientras que, en la mayoría de barrios de ingresos altos, existe una creciente demanda por uso de automóvil privado, en los barrios periféricos y de bajos ingresos, la demanda se divide en aquellas personas que disponen de una mejor accesibilidad a los medios formales de transporte público y aquellas personas que solo disponen de transporte público informal, que en su mayoría se encuentra en un estado degradado y son inseguros (Figueroa, 2005).

El presente artículo tiene como objetivo ilustrar la problemática de la población urbana que reside en áreas periféricas de bajos ingresos tomando como estudio de caso un proyecto de vivienda de interés social en el municipio de Soacha (Colombia), desde una perspectiva que involucra la movilidad cotidiana. El tema es importante porque permite hacer un análisis, a partir de un estudio de caso, sobre la realidad que vive una población de bajos recursos con relación a la segregación vista desde la movilidad cotidiana.

\section{El poblamiento de las periferias populares de Bogotá. El caso del municipio de Soacha}

Las nociones de segregación mencionadas adquieren sentido para esta investigación en tanto permiten aproximarse a ese fenómeno de emergencia de un conjunto urbano monoclasista de carácter popular en el eje sur de expansión de Bogotá. Fenómeno ocurrido en el avance espontáneo de la metropolización, y de aquí el interés 
por analizar si los nuevos desarrollos inmobiliarios residenciales promovidos bajo la figura de los 'Macroproyectos de Vivienda de Interés Social (MISN)' promovidos por el nivel central de gobierno, en particular el proyecto Ciudad Verde, ubicado en el municipio conurbado de Soacha (al sur de la ciudad capital), contribuye a incrementar el distanciamiento social y físico de sus residentes con los del resto del conjunto metropolitano.

Para ejemplificar esta situación, Alfonso (2009b) menciona que un municipio monoclasista de rango bajo es el municipio de Soacha, ubicado a 10 km de Bogotá. Este es considerado como municipio conurbado, presenta un crecimiento urbano más dinámico en comparación con otras ciudades, con el hecho de ser receptor de población víctimas de desplazamiento forzado, llegadas de otras regiones del país (Alfonso, 2010 , p. 13). Así mismo, existe un gran número de industrias que requieren gran cantidad de mano de obra no calificada que se consigue en el municipio. Por otro lado, hay un gran número de trabajadores que, si bien residen en Soacha, tienen su función primaria en la ciudad capital, como se observa en la figura 2.

La identificación de Soacha como municipio metropolizado se corrobora principalmente en sus aspectos poblacionales, ya que, según cifras censales (2005), en Bogotá, el $38 \%$ de la población nació en otro municipio o en el exterior, mientras que en Soacha esta cifra es del 82,1 \% (Alfonso, 2009b). Esta situación es similar en Mosquera, pues ambos municipios, en
Figura 2. Desplazamientos residencia-trabajo (área urbana). Bogotá (\%). 2005

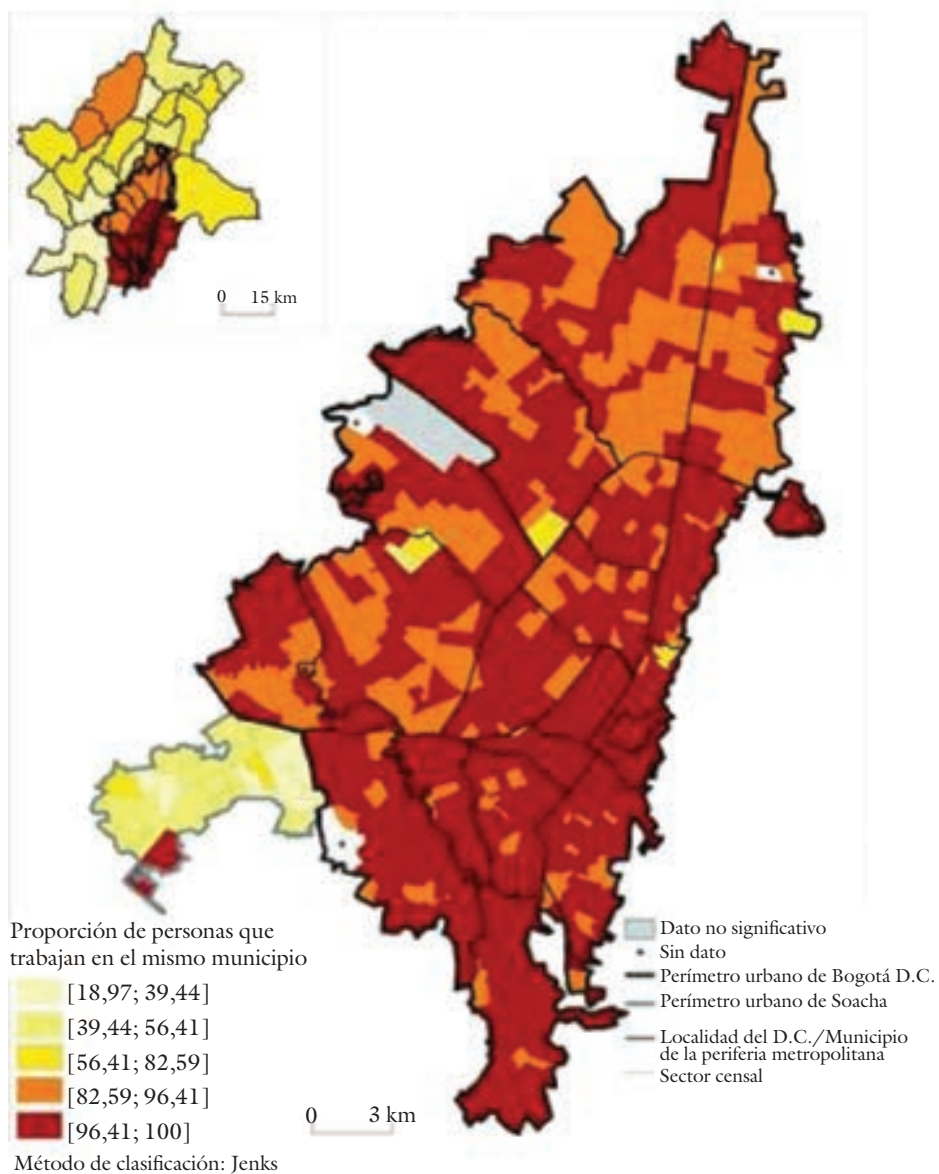

Fuente: ANR Metal 2010 y DANE.

comparación con Bogotá, poseen un suelo urbanizable más económico, por lo tanto, los proyectos de vivienda de interés social se pueden construir a 'un menor precio' que en el interior de la ciudad, lo que fa- territarias 31 141 
${ }^{1}$ Ley 1469 de 2011, "por la cual se adaptan medidas para promover la oferta de suelo urbanizable y se adoptan otras disposiciones para promover el acceso a la vivienda". Recuperada de http://camacol.co/sites/default/files/base_datos_juridico/ley $1469 \% 20$ de $\% 20$ 2011.pdf tersitarias 31 142 vorece la creación de viviendas sociales en los municipios fronterizos de las ciudades principales, como es el caso de Santiago de Chile y Bogotá (Lévy \& Brun, 2002).

Soacha, hoy en día, presenta una nueva ola de crecimiento demográfico, a través de algunos grandes proyectos urbanos que lo han impulsado. Uno de estos casos es el macroproyecto ${ }^{1}$ Ciudad Verde, que pretende construir 42.000 viviendas, principalmente en conjuntos residenciales, y se proyecta a una población de alrededor de 160.000 habitantes. Actualmente, se han entregado 8.000 viviendas, de las cuales hay aproximadamente 7.000 habitadas. Es un terreno de más de 320 hectáreas (ha), cuya oferta promete que contará con todo el equipamiento necesario para esta población. En la actualidad, hay un colegio, un centro comercial, grandes zonas verdes, y se proyecta construir un hospital y una estación de policía. En la práctica, este es un proyecto que cumpliría con lo que cualquier persona de bajos recursos desearía, tanto es así que, entre los habitantes de Soacha, este proyecto ya es conocido como 'Narnia' (figura 3).

\subsection{Ciudad Verde}

El macroproyecto Ciudad Verde, ubicado en el municipio de Soacha, se realiza en el marco de la Ley 1469 de 2011; en este sentido, en el texto de la mencionada ley,

Figura 3. Actual colegio en Ciudad Verde

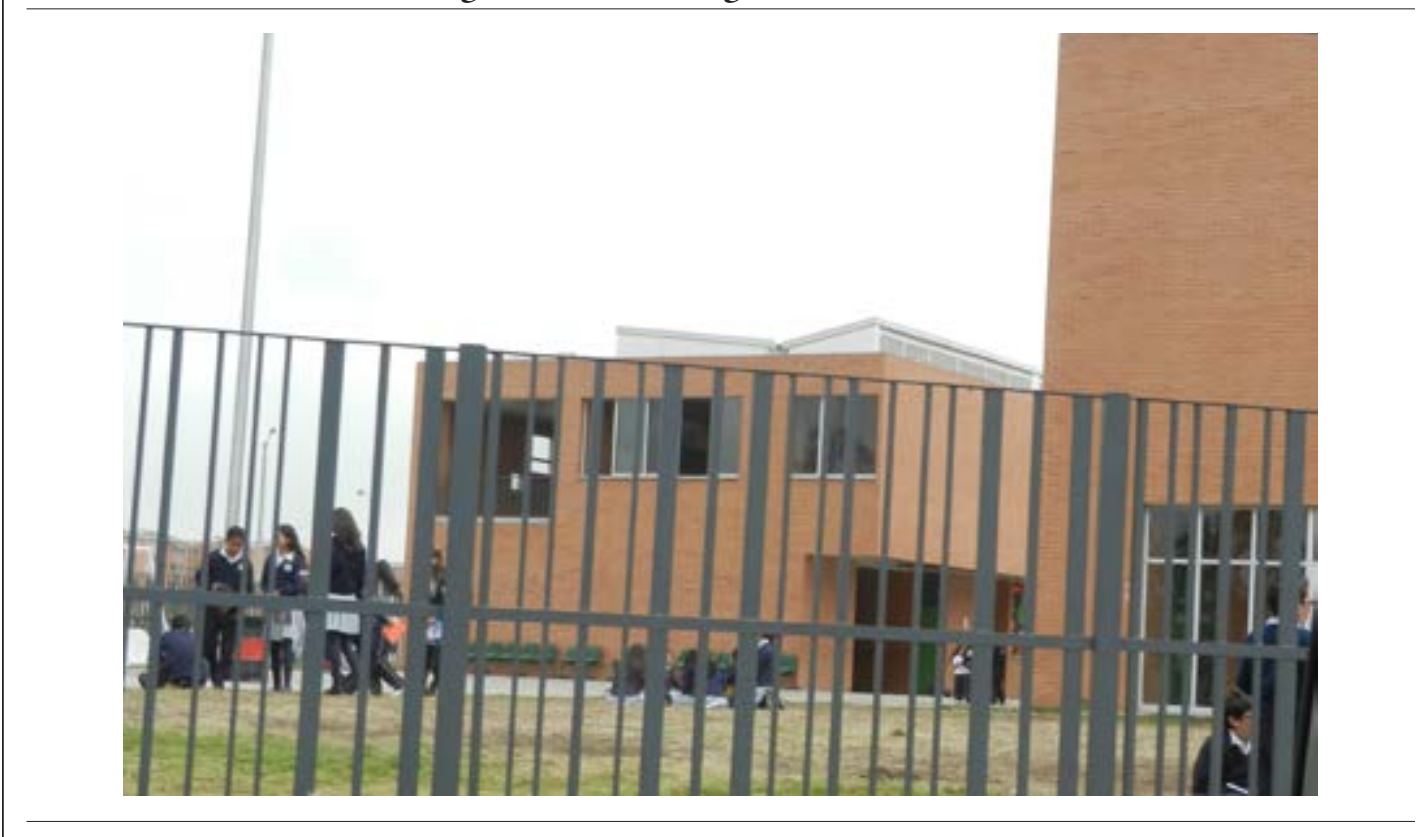

Fuente: tomada por los autores. 
se describen los mecanismos mediante los cuales es posible que los municipios habiliten suelo para desarrollar los proyectos:

¿Qué son los macroproyectos de interés social nacional? Según el artículo $2^{\circ}$, capítulo II, de la Ley 1469 de 2011, se establece que los macroproyectos de interés social nacional son el conjunto de decisiones administrativas y de actuaciones urbanísticas, definidas de común acuerdo entre el gobierno nacional y las administraciones municipales y distritales en el ámbito de sus respectivas competencias, para la ejecución de operaciones urbanas integrales de impacto municipal, metropolitano o regional que garanticen la habilitación de suelo para la construcción de vivienda y otros usos asociados a la vivienda y la correspondiente infraestructura de soporte para el sistema vial, de transporte, de servicios públicos, espacios públicos y equipamientos colectivos (ver figura 4). Los macroproyectos de interés social nacional deberán atender de forma preferente el déficit de vivienda de la respectiva entidad territorial y establecer mecanismos para asegurar que los hogares

Figura 4. Usos del suelo en Ciudad Verde

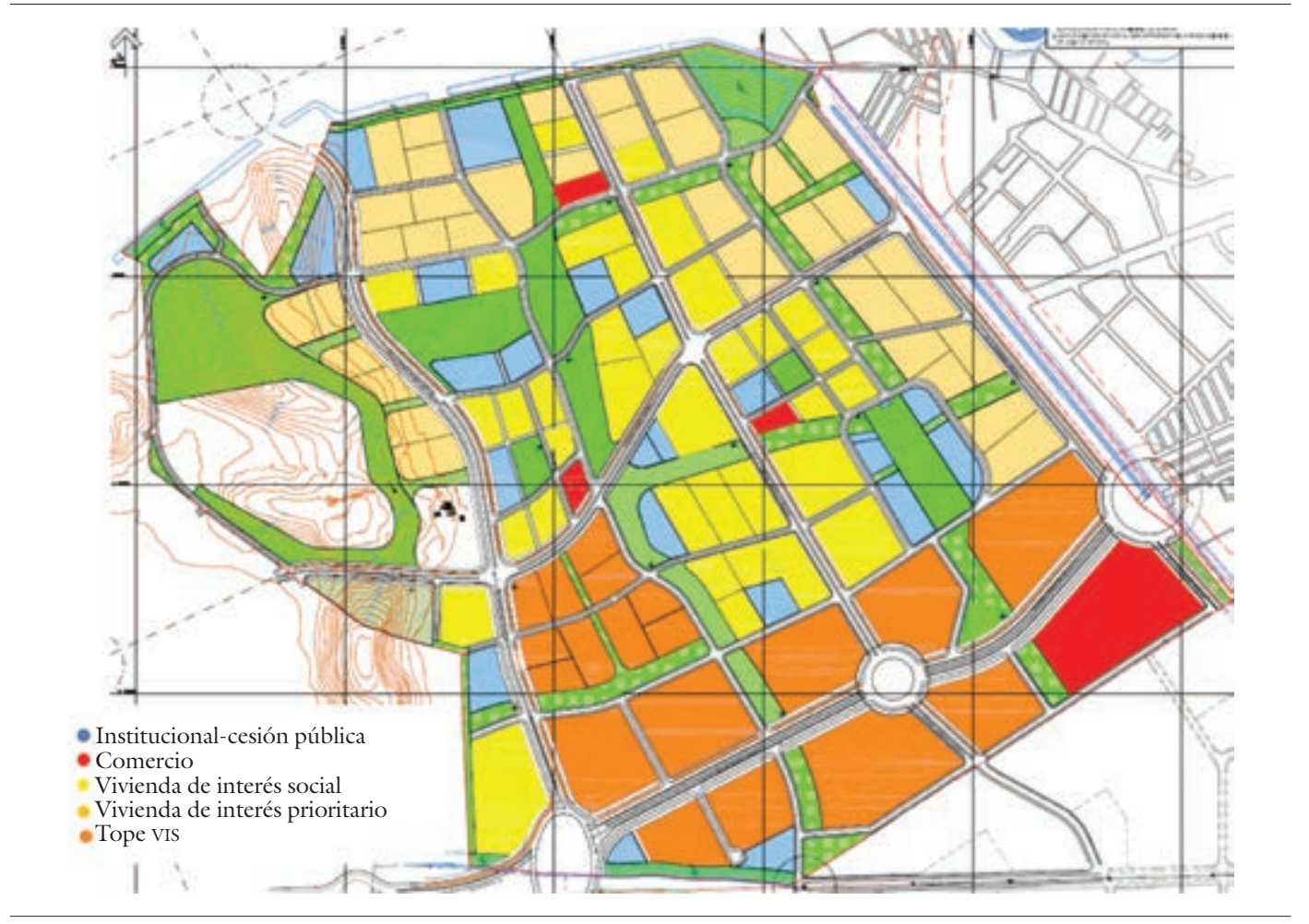

Fuente: cortesía de Amarilo. 
2 "Por medio de la cual se adopta, por motivos de utilidad pública e interés social, el macroproyecto de interés social nacional 'Ciudad Verde' en el municipio de Soacha, Cundinamarca”.

${ }^{3}$ A la fecha de elaboración del artículo, el TransMilenio hasta Soacha no estaba funcionando. Entró en operación en diciembre de 2013, con cuatro estaciones en servicio. Actualmente, en el proyecto, se están analizando los impactos de la entrada de la extensión del TransMilenio.

${ }^{4}$ Información tomada de http://www.ciudadverde. com.co/ciudad-perde/descripcion-general

\section{tersitarias 31}

de menores ingresos y la población vulnerable puedan acceder a las soluciones habitacionales que produzcan los macroproyectos.

En la Resolución 1687 de 2009 del Ministerio de Ambiente, Vivienda y Desarrollo Territorial, ${ }^{2}$ se presentan, a modo de diagnóstico, diferentes motivaciones para el desarrollo del macroproyecto en la jurisdicción de Soacha, mencionando, entre otros, que la proximidad del municipio con Bogotá es innegable, con el efecto de tener un componente supramunicipal para pensar la resolución de las problemáticas urbanas, como el déficit cuantitativo habitacional, agravado por el déficit cualitativo de Soacha. Específicamente, se indica que

el diagnóstico de la situación de la vivienda en el municipio de Soacha tiene una particular complicación por las características propias del urbanismo y la tipología habitacional existente. Una de las características habitacionales del municipio es la inexistencia de los estratos de altos ingresos en su interior y la fuerte presencia de los estratos uno y dos, que se expresa en la mancha urbana por medio de altos índices de necesidades básicas insatisfechas reflejados en la calidad de la vivienda y en la inexistencia de algún servicio básico (Res. 1687/09, p. 2).

El macroproyecto (figura 5 y 6 ) fue vendido a la población con la idea inicial de que el TransMilenio iba a llegar hasta Soacha, lo que permitiría tener al alcance de la población residente un acceso a este sistema, algo de fundamental importancia, que, de acuerdo con Lungo (2007, p. 266), señala que "la provisión de sistemas adecuados de transporte público podría desempeñar un papel central para mejorar la calidad de vida de las crecientes ciudades latinoamericanas".

Desafortunadamente, debido a factores políticos, sociales y económicos, el TransMilenio hasta Soacha lleva un retraso de más de dos años y, aun cuando se construyó una gran parte de su infraestructura (estaciones, la calzada exclusiva, puentes peatonales), no ha entrado en funcionamiento. ${ }^{3}$ Hoy en día, muchas de estas estaciones ya se encuentran en un alto grado de deterioro y vandalismo, habitantes de la calle las han empleado como lugar para dormir y para hacer sus necesidades fisiológicas. Según la actual administración, se menciona que, para finales de 2013 , estaría entrando en funcionamiento el TransMilenio, lo que en la práctica podría traer beneficios para la población del macroproyecto, aunque se ha argumentado que por el momento no habrá rutas alimentadoras hasta Ciudad Verde.

Es importante contextualizar el proyecto para entender sus dimensiones e implicaciones; de esta manera, la descripción general del proyecto ${ }^{4}$ es la siguiente: el macroproyecto se desarrolla sobre un terreno de 328 ha en límites con la localidad de Bosa. La denominación como 'Ciudad Verde' se explica por la extensa cantidad de zonas verdes y parques lineales, disponibles y estimados en 57 ha (figura 7 y 8 ). 
Figura 5. Mapa del macroproyecto Ciudad Verde en Soacha

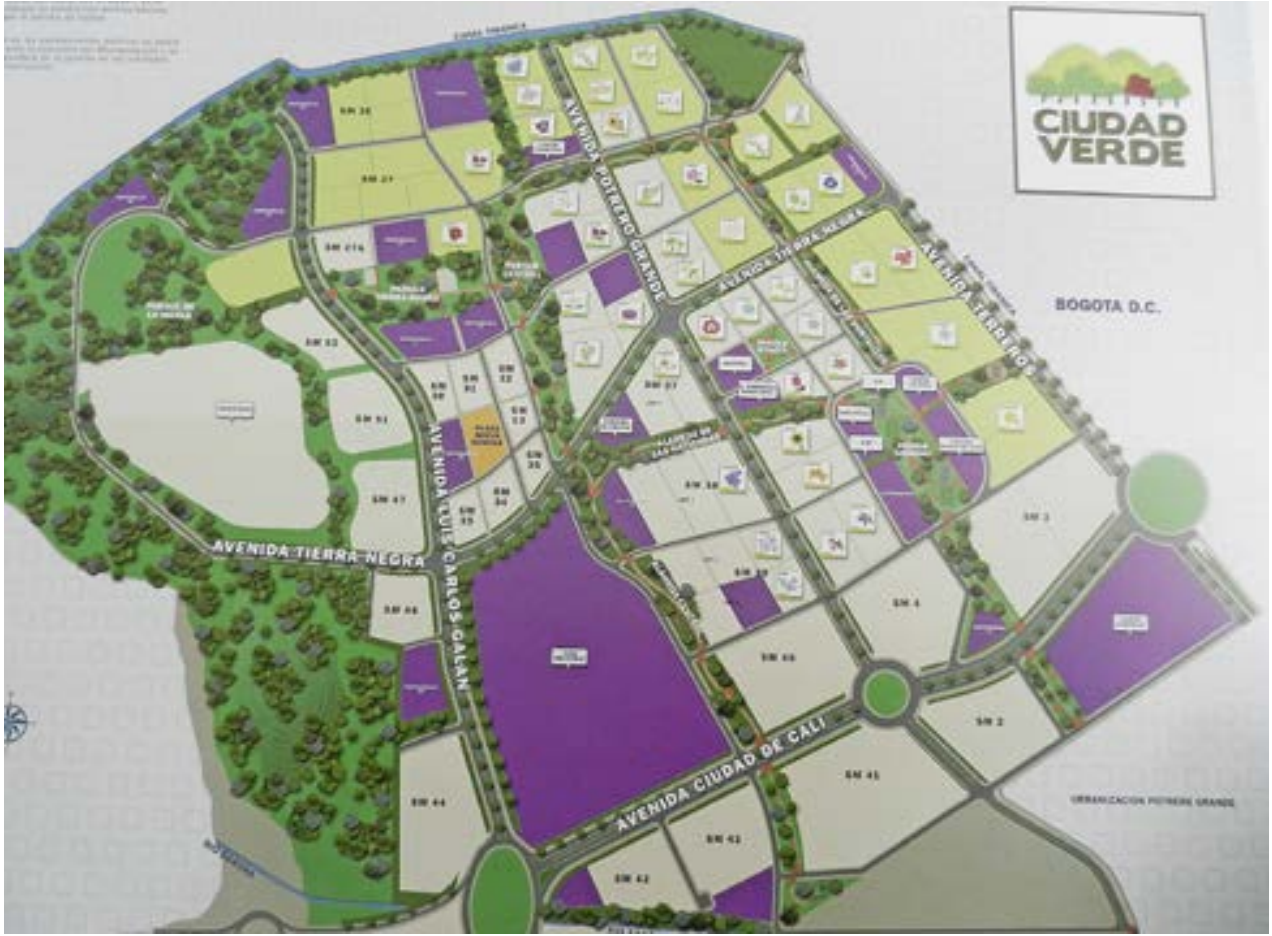

Fuente: www.amarilo.com

Figura 6. Ingreso a Ciudad Verde

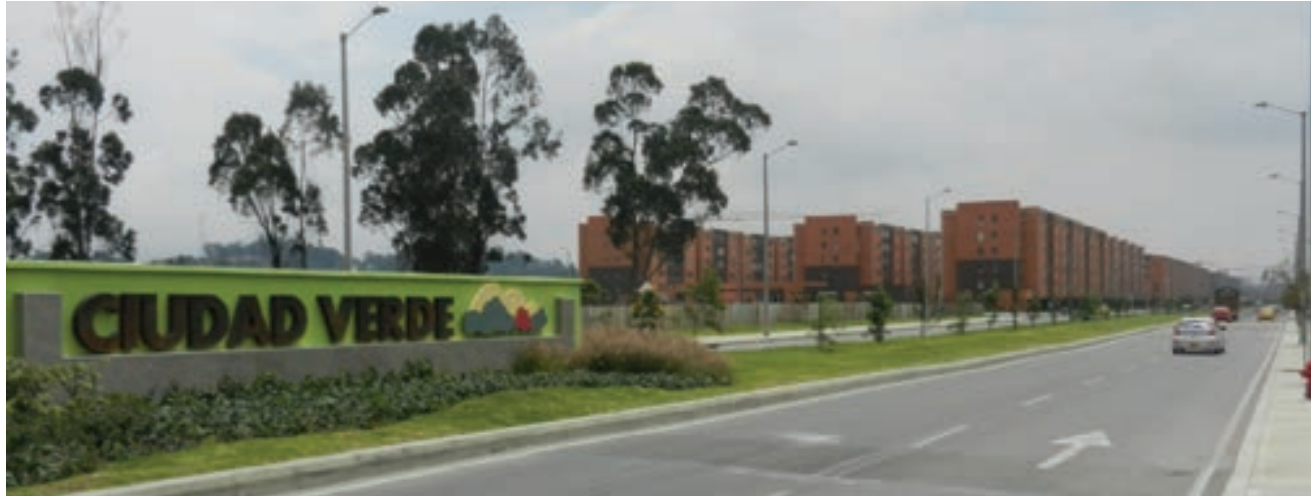

territarias 31

SEGREGACIÓN RESIDENCIAL Y MOVILIDAD COTIDIANA EN EL CONTEXTO METROPOLITANO 
Figura 7. Vías de acceso a Ciudad Verde

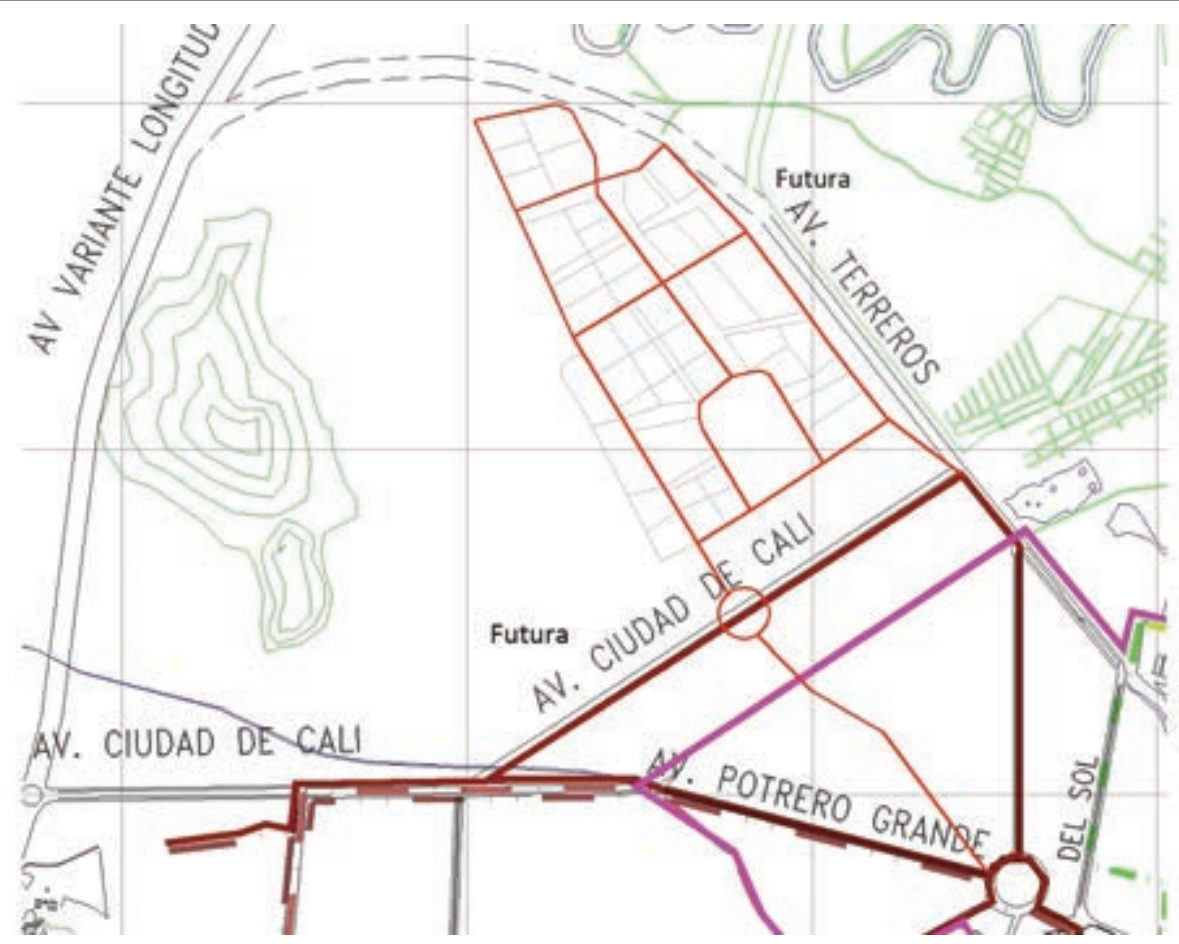

Fuente: http://www.skyscrapercity.com/showthread.php?t=1088315

\section{Enfoque metodológico}

La investigación tiene un enfoque cualitativo y se desarrolla en forma de un estudio de caso acerca de las interrelaciones entre Bogotá y Soacha. Además, se complementa mediante la revisión documental y entrevistas semiestructuradas a residentes y actores involucrados en las áreas de estudio.

Para el análisis de información secunterritarias 31 146 daria, se aplica la estrategia de investigación documental, la cual, conforme con Uribe (en Paramo, 2011), es un estudio metódico de diferentes fuentes de índole permanente (documentos escritos, información impresa, etc.) que sirven para el entendimiento del problema que se está estudiando o para definir nuevos acontecimientos o situaciones que permiten la construcción de conocimiento. En una primera instancia, la investigación es documental, como menciona Alfonzo (en Uribe, 2011), la investigación documental se agrupa, dependiendo su naturaleza y profundidad analítica, en informativa y argumentativa. Para fines de 


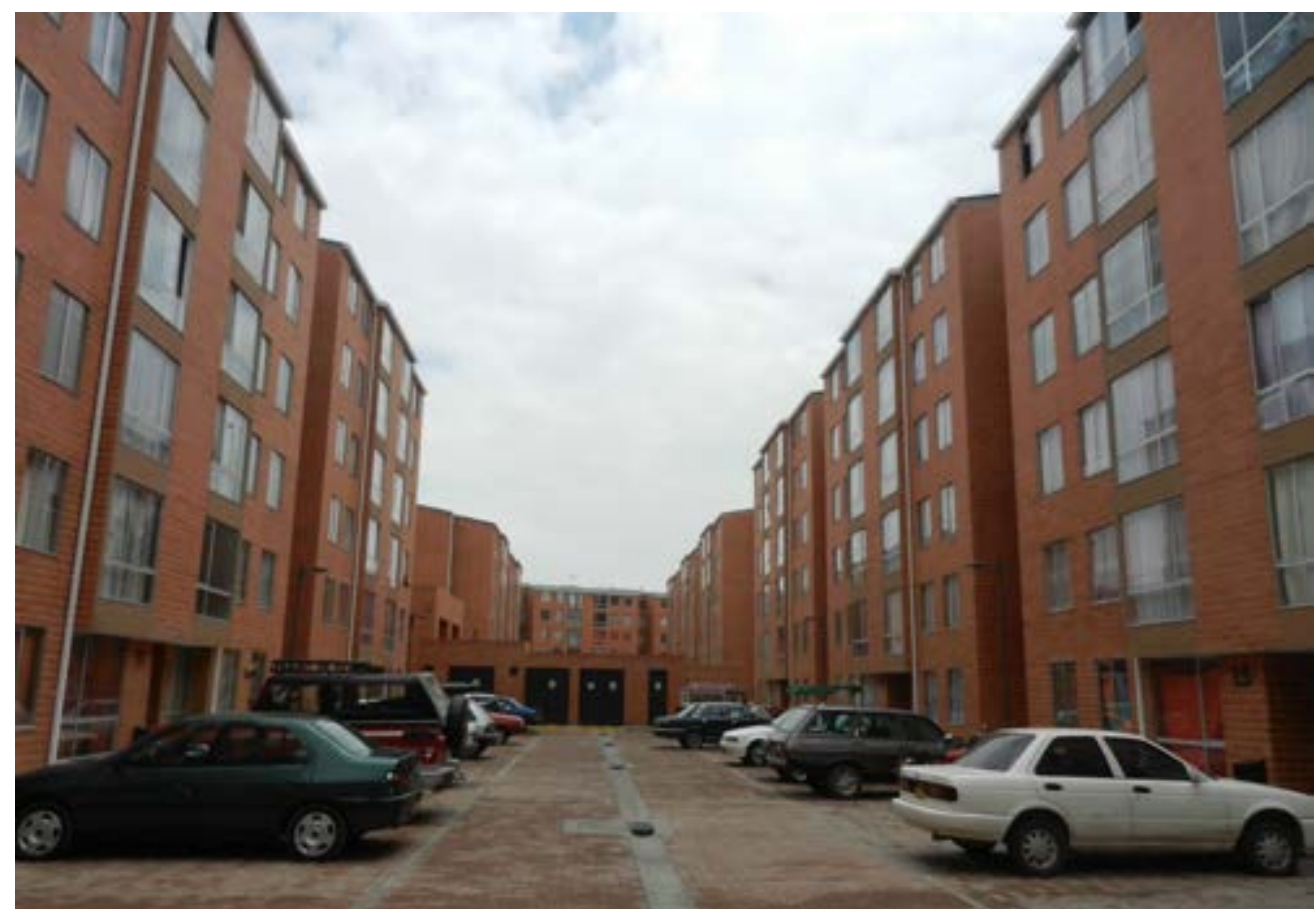

Fuente: tomada por los autores.

esta investigación, se realiza una investigación de tipo informativo, que comprende la revisión de la información relevante que se obtiene después del estudio y recopilación de fuentes confiables sobre el tema o área que se está investigando sin profundizar en el análisis de tales datos.

El estudio de caso, según Yin (2009), es una indagación que investiga un fenómeno contemporáneo en profundidad y en su contexto real, especialmente cuando los límites entre el fenómeno y el contexto no son claramente evidentes. La ventaja de este procedimiento es que permite acercarse a la particularidad, entonces, es "el estudio de la particularidad y de la complejidad de un caso singular, para llegar a comprender su actividad en circunstancias importantes" (Stake, 2010, p. 11). La aplicación del estudio de caso permite al investigador tener varias técnicas y/o estrategias de investigación (entrevista, encuestas, observaciones) a la hora de realizar la recolección de la información (Moncayo, 2011).

La técnica de recolección de información es efectuada con base en las entrevistas 
${ }^{5}$ Los conjuntos residenciales en donde se realizaron encuestas fueron: Caléndula, Arrayán, Trébol, Papiro, Magnolia, Geranio, Palo de Rosa, Frailejón I, Acanto I, Acanto II, Victoria II y Agapanto.

\section{territarias 31} 148 en profundidad, las cuales son una "técnica diseñada con el fin de provocar un retrato vívido de las perspectivas del participante en el tópico de investigación en el que está interesado el investigador" (Páramo, 2008 , p. 125), por lo que se llevan a cabo encuestas a un número de habitantes en Ciudad Verde.

Para el levantamiento de la información, se hicieron 245 encuestas a los residentes de Ciudad Verde, las cuales fueron seleccionadas mediante un diseño muestral con base en el total de viviendas habitadas ${ }^{5}$ a la fecha de la realización de las encuestas. La información secundaria se obtuvo a partir de entrevistas en profundidad efectuadas a los administradores que cobijaron los conjuntos seleccionados en la muestra (cuatro administradores). Además, se entrevistó al gerente del proyecto inmobiliario.

\section{Resultados preliminares}

El anhelo de tener vivienda propia es un deseo de muchos habitantes de la ciudad, y, en la mayoría de los casos, la decisión de la ubicación de la vivienda se basa en la compensación entre el aumento en el costo del transporte (tiempo y dinero) al trabajo y la disminución en el precio por unidad de la vivienda, como señalan Weisbrod, BenAkiva y Lerman (1980). En este sentido, un gran número de residentes en Ciudad Verde provienen de la capital en búsqueda de una vivienda propia, a un precio mucho más accesible que en la misma ciudad, como se observa en la figura 9. Varios de estos habitantes han sacrificado el tiempo de recorrido a su trabajo, que en muchos casos es mucho más económico (tiempo y dinero) en la ciudad capital que en los municipios vecinos, por el hecho de tener vivienda propia, como se ve en la figura 10.

Figura 9. Municipio en donde residía anteriormente

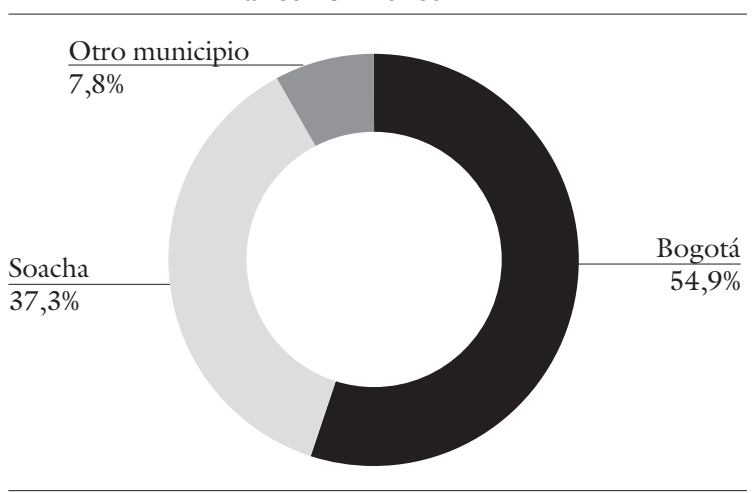

Fuente: elaboración de los autores, construida con base en las encuestas realizadas.

Vale aclarar que, en el macroproyecto Ciudad Verde, existen dos conjuntos residenciales (Acanto I y Acanto II), que fueron otorgados de manera gratuita a la población afectada por la ola invernal de 2010 de los barrios Cazucá y San Mateo, ubicados en el municipio de Soacha. Si en el análisis de los datos incluimos las razones de cambio de vivienda de los residentes de Acanto I y II, los resultados fueron un poco diferentes. Es importante mencionar que en estos dos conjuntos se llevó a cabo casi una tercera parte de las encuestas realizadas.

En la figura 10, se observan las principales razones que tuvieron en cuenta 
los habitantes a la hora de pasarse a vivir a Ciudad Verde. El hecho de mejorar la localización, como respuesta que dieron los encuestados, hace referencia principalmente al proyecto en sí; es decir, el proyecto se vende muy bien, puesto que la zona y el equipamiento que posee es de muy altos estándares en comparación con muchos otros proyectos de vivienda de interés social o prioritario en el país, por lo que muchos residentes se vieron atraídos por las ventajas y beneficios que este les ofrecía: espacios verdes, amplias vías de acceso, parques, centro comercial, entre otros.

Si bien es cierto que se resaltan las principales razones para cambiar de vivienda (figura 10), este proceso es algo mucho más complejo que el simple hecho de querer adquirir una vivienda propia o mejorar la vivienda o la localización, ya que una "estrategia de comportamiento espacial resulta ser un proceso bastante complejo, que exige un arbitraje entre múltiples dimensiones que compiten entre sí pero que corresponden a distintas escalas temporales" (Garretón, 2011, p. 39).

La condición contractual de los encuestados se puede observar en la figura 11 , en donde se aprecia que el $29 \%$ trabaja como empleado en una empresa privada o pública, el $26 \%$ es trabajador familiar sin remuneración, el $24 \%$ es trabajador infor-

Figura 10. Razón de cambio de acuerdo con ubicación donde residía antes (sin Acanto I y II)

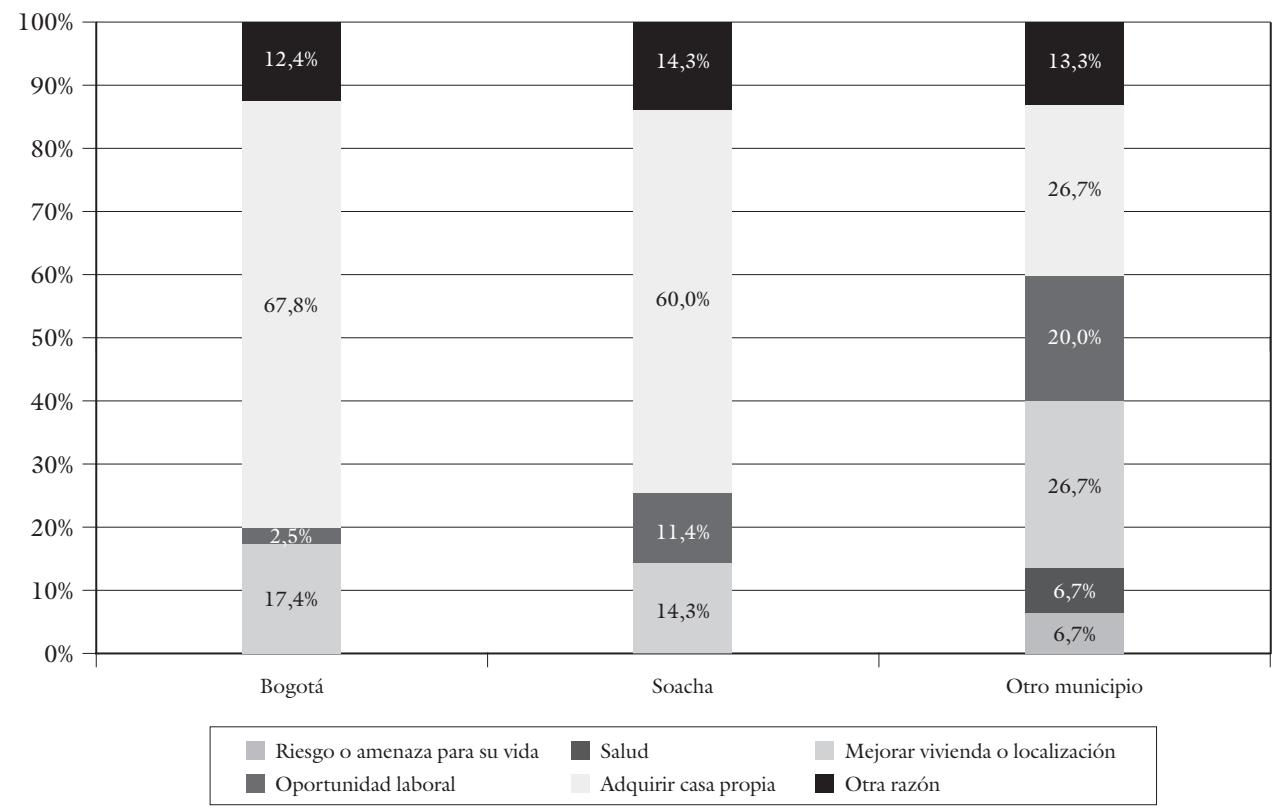

Fuente: elaboración de los autores, construida con base en las encuestas realizadas. 
Figura 11. Condición contractual

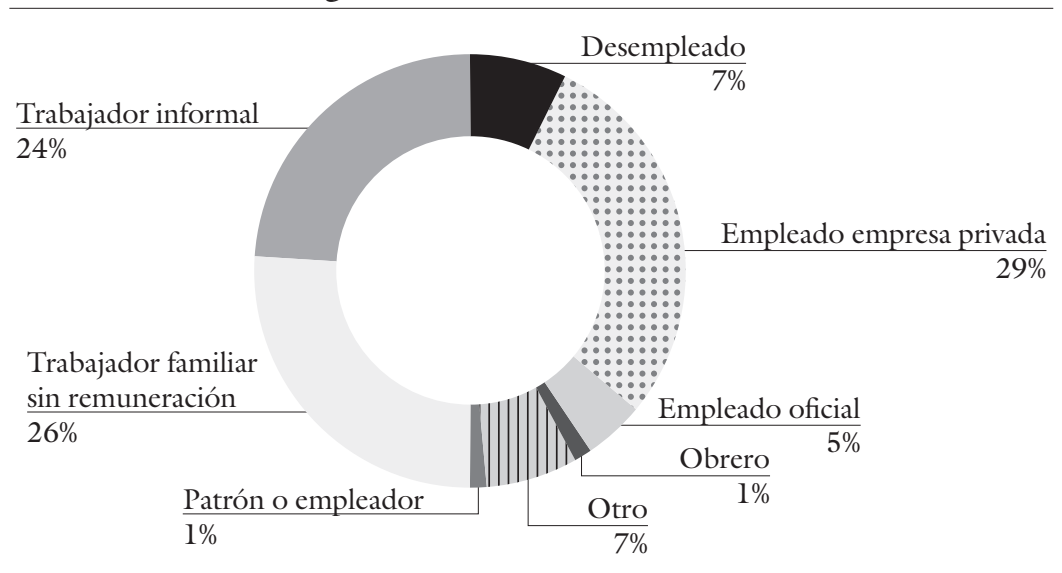

Fuente: elaboración de los autores, construida con base en las encuestas realizadas.

mal y el $7 \%$ es desempleado. Esto nos permite ver que existe un alto porcentaje de la población de Ciudad Verde que no cuenta con un trabajo estable y que debe recurrir, en muchos casos, a 'rebuscar' el dinero para llevar al hogar. Si a esto se le agrega la obligación de pagar por una administración, la situación se agrava para esta población.

Se han tomado medidas para contrarrestar y disminuir los problemas que puede traer para el conjunto y la persona (hogar) el no pagar la administración. En algunos conjuntos, se ha tomado la decisión de adecuar un tipo de alcancía de tal manera que al final del día el residente deposite en dicha alcancía la cantidad de dinero que pueda, y, al final del mes, se mira cuánto se ha recogido y esto va para el pago de la cuota de administración. Sobre todo, se hace esto con aquellos residentes que no tienen un ingreso fijo mensual, que no saben si al final del mes van a poder contar con el di- nero para pagar no solo la administración, sino los servicios públicos (gas, acueducto, energía), cuota al banco por el préstamo o el arriendo (según sea el caso).

La figura 12 presenta la percepción de los residentes en cuanto a si el tiempo de desplazamiento mejoró, empeoró o siguió igual, de acuerdo con su condición contractual. La figura 13 muestra algo parecido, pero contabilizando el tiempo que se demoran en los trayectos de ida a su empleo y de regreso a su casa. El tiempo de desplazamiento es un aspecto que se ha tenido en cuenta con el fin de observar el grado de segregación al que puede estar sometido una sociedad o población específica; es así que, según Garretón (2011): "El presupuesto temporal de desplazamiento, de poco más de una hora diaria por persona y con pocas variaciones, ha ejercido una enorme influencia en el estudio de la accesibilidad urbana. De hecho, uno de los indicadores más simples de accesibilidad es la cuantificación de las oportunidades en las que se puede llegar en un tiempo inferior a un cierto límite" (p. 40).

Pero, al mismo tiempo, la relación entre el trabajo y el lugar de residencia sugiere que el crecimiento de las distancias está, en parte, ligado al fenómeno de la periurbanización (Polacchini, 1999), caso que acontece con el municipio de Soacha.

Como se mencionó anteriormente, aunque existía alguna infraestructura del sistema de transporte masivo TransMilenio en Soacha, la promesa sobre el inicio de su funcionamiento solo se concretó recientemente. Esta demora puede verse como

\section{territarias 31} 150 
Figura 12. Desplazamiento en tiempo de acuerdo con condición contractual

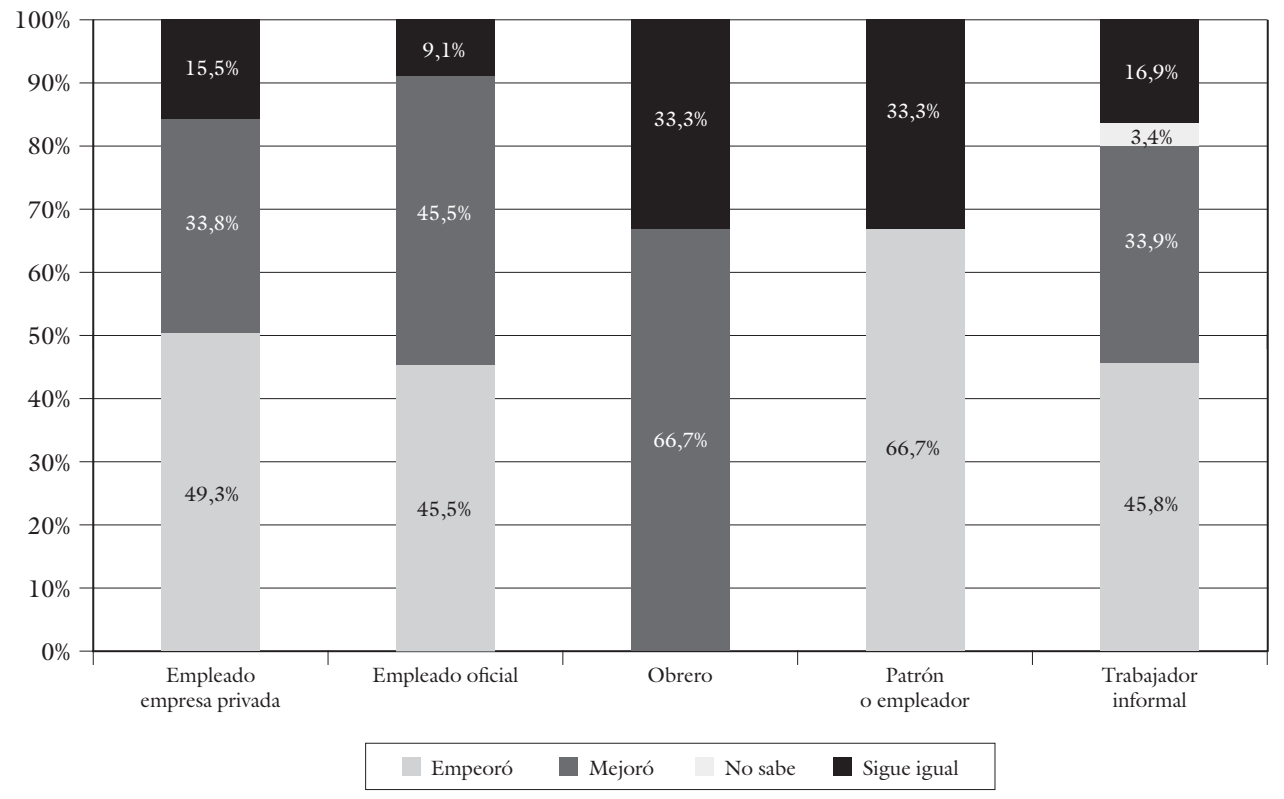

Fuente: elaboración de los autores, construida con base en las encuestas realizadas.

Figura 13. Tiempo que se demora en ir y volver al sitio de trabajo

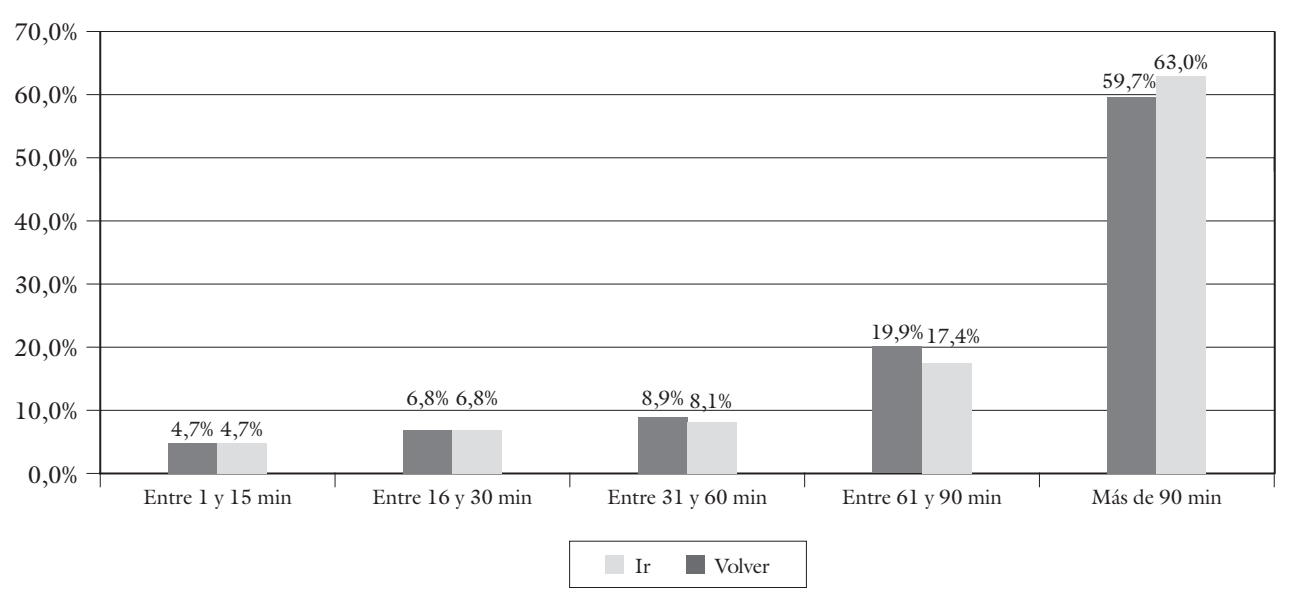

Fuente: elaboración de los autores, construida con base en las encuestas realizadas. 
consecuencia de la falta de una autoridad metropolitana de transporte, ocasionando que el único medio de transporte que ha podido llegar hasta Ciudad Verde, después de varios problemas y enfrentamientos entre los transportadores del municipio de Soacha y algunos de los líderes de Ciudad Verde, han sido unas pocas rutas de servicio público que llegan hasta algunas zonas de la capital (figura 14).

Desafortunadamente, el problema del transporte formal es algo recurrente, no se ha dado una solución concreta a los graves problemas de movilidad que presentan a diario los habitantes. Conforme con palabras de uno de los administradores de los conjuntos: “... se hizo una inspección a las cuatro de la mañana conmigo y se dio cuenta que habían alrededor de unas 300 o 400 personas que salían a conseguir transporte y que, si llegaban a las cuatro de la mañana, les daban las siete u ocho de la mañana y no habían alcanzado a coger transporte, por una sencilla razón, porque llegaban 5 o 6 carros..." (entrevista efectuada a uno de los administradores de los conjuntos de Ciudad Verde, 28 de octubre de 2013).

Ante esta situación de precariedad de la movilidad, se empiezan a presentar $\mathrm{co}^{-}$ mo alternativa los transportes informales e ilegales, que cumplen con la función de acercar y brindar a los residentes un medio de movilidad, el cual no fue suministrado de manera eficiente por el gobierno local y

Figura 14. Estacionamiento de las rutas de transporte público de Ciudad Verde

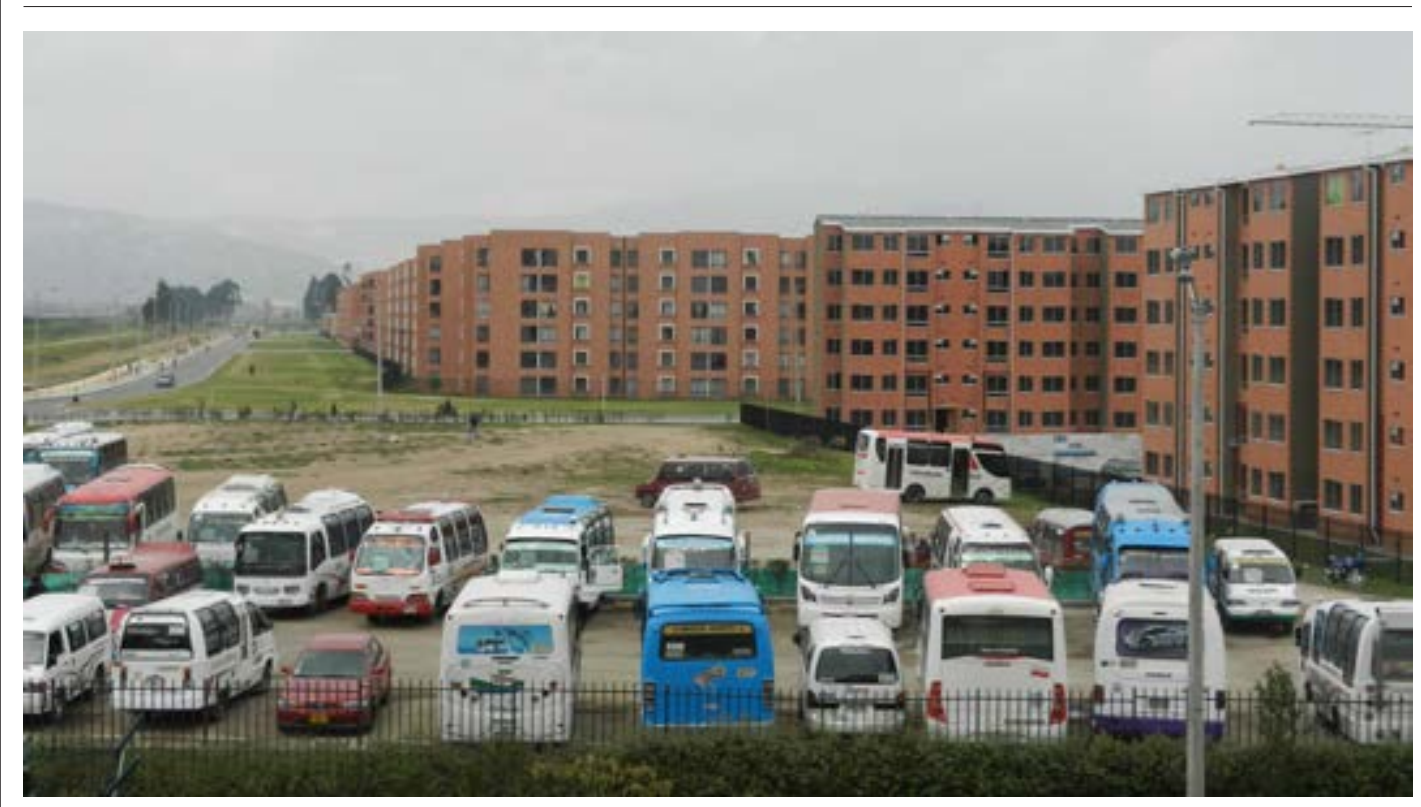

Fuente: tomada por los autores. 
por las autoridades encargadas de este fin, añadiendo una variable más de exclusión, ya que, en este contexto, como lo menciona Coutras (en Avellaneda, 2007, p. 152), "las políticas de transporte serán una herramienta para la inserción o cohesión social, o, por el contrario, una herramienta más de exclusión". En ese mismo lineamiento, y según lo expresa Miralles (2002), cuando los desplazamientos que realizan las personas están relacionados de manera directa con la utilización de los diferentes modos de transporte, se introduce una nueva forma de desigualdad.

En este sentido, la población residente en esta apartada zona ha tenido que incurrir en gastos adicionales de transporte, tomando, en muchos casos, más de un servicio de transporte para poder llegar a su lugar de trabajo. Es así que esta ubicación retirada de los servicios públicos formales e, incluso, del sistema TransMilenio hace que los tiempos de desplazamiento sean mayores que en otras áreas de la misma ciudad de Bogotá y con mayores costos, llevando a que la población se vea afectada por esta medida.

Si bien el proyecto Ciudad Verde cuenta con toda la infraestructura que puede necesitar cualquier persona para vivir de una manera digna: acueducto, alcantarillado, electricidad, gas natural, esto no es suficiente, en gran medida por la ausencia de una forma de transporte que les permita desplazarse de forma más eficiente al lugar de trabajo y/o educación, tal como lo menciona Ávila (2003, p. 8): "La existencia de un transporte colectivo eficiente y accesible para la población más pobre puede aumen-

Figura 15. Modo de desplazamiento de quienes trabajan

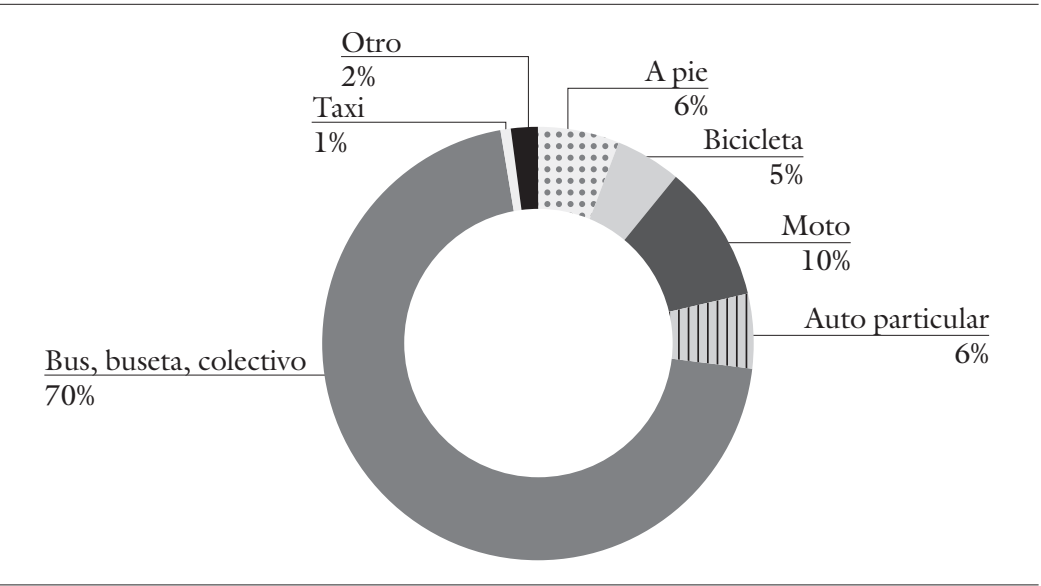

Fuente: elaboración de los autores, construida con base en las encuestas realizadas.

tar considerablemente la disponibilidad de su ingreso y del tiempo de los más pobres... En este sentido, se entiende el transporte colectivo como una herramienta importante para combatir la pobreza urbana y de promoción de la inclusión social". Las formas de desplazamiento de los habitantes de Ciudad Verde se pueden observar en la figura 15.

Para la gran mayoría de habitantes de Ciudad Verde, el transporte es uno de los grandes problemas que han tenido que afrontar, teniendo que pagar hasta tres transbordos antes de llegar a su destino final, lo que significa mayores gastos en el hogar. Algunos habitantes optan por madrugar para poder tomar una de las rutas disponibles que llegan hasta algunas partes céntricas de Bogotá, lo que les reduce notoriamente los gastos adicionales de transbordo. Pero esta no es la situación para territarias 31

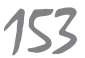


${ }^{6}$ Los nombres de los entrevistados fueron cambiados paramantener suanonimato. territarios 31 154 otro gran número de habitantes que no pueden madrugar porque tienen que llevar los hijos al colegio o porque simplemente no les sirven las 4 o 5 rutas que transitan por Ciudad Verde. En este caso, el medio de transporte está muy asociado no solo con el ingreso de las familias (Avellaneda, 2007), sino también con su disponibilidad.

Los trabajadores se han visto afectados por la situación de la movilidad, al punto que se ha tenido conocimiento de distintos casos en los que alguno de los familiares se ha visto forzado a renunciar a su trabajo, debido a que no pueden llegar a tiempo, lo que puede ser observado como un factor de desempleo (Cebollada \& Miralles, 2009) y de segregación. Como lo menciona uno de los administradores de los conjuntos residenciales de Ciudad Verde:

... nos levantamos a las cuatro de la mañana, salimos a las cinco y son las siete de la mañana y no hemos cogido transporte, tenemos problemas en nuestro trabajo porque le decimos a nuestro jefe: "Mire, es que nosotros vivimos en Soacha”. Y él nos responde: "Ese no es mi problema, señor, yo lo contrato y, si no nos llega a la hora, lo lamento, pero se tiene que retirar de Ciudad Verde o conseguir algo más cerca de acá, o retirarse del trabajo y conseguir algo cerca a Ciudad Verde..." (entrevista efectuada a uno de los administradores de los conjuntos de Ciudad Verde, 28 de octubre de 2013).

Pero no solo los jefes del hogar son quienes se han visto afectados por la falta de transporte, también sus hijos en muchos casos han tenido que sufrir las consecuencias. En primer lugar, porque en Ciudad Verde la infraestructura educativa no es la suficiente para la población en edad escolar en la ciudadela, y, a medida que van llegando más personas, el problema se agrava. Por lo tanto, muchos padres se han visto en la necesidad de incurrir en un nuevo gasto que anteriormente no tenían: el transporte escolar.

En varios casos, el distanciamiento de los estudiantes al centro educativo ha llevado a que muchos de ellos tengan que dejar de estudiar, ya que no existen los medios económicos para poder pagar su transporte escolar. Anteriormente estaban ubicados a una distancia a la cual los niños y muchachos podían ir caminando sin necesidad de recurrir en costos adicionales de transporte. Esto puede generar que los niños, niñas y adolescentes se vean afectados en su educación o en la calidad de ella, por lo tanto, el transporte vuelve a ser pieza fundamental para aumentar la participación escolar (SEU, 2003). Es tal el problema que han vivido algunas de las familias que han tenido que retirar del colegio a los niños por cuestiones económicas, como lo afirma Claudia, ${ }^{6}$ habitante de Ciudad Verde:

En cuanto a la educación, ha sido muy complicado, pues venir gente de la loma, donde tienen escuelitas de barrio ahí pegadas y llegar acá donde no hay absolutamente nada, pues la gente se ve muy afectada; incluso, muchas familias sacaron a sus hijos de estudiar, demasiadas, porque es que el transporte para ir a la loma donde estaban sus hijos es- 
tudiando se les iba siete mil, ocho mil pesos diarios ida y vuelta, y una persona que tiene escasamente cinco mil pesos pa'l diario era imposible. Entonces, muchas familias sacaron a sus hijos de estudiar debido a eso, pues porque aquí no lo solucionaron (entrevista efectuada a Claudia, habitante de Ciudad Verde, 28 de octubre de 2013).

Como se puede observar en la figura 16, la mayoría de los empleados de empresas privadas y oficiales gastan en promedio entre 3,2 y 4,2 dólares por día, lo que representaría entre 64 y 84 dólares al mes (asumiendo 20 días laborales al mes), contando solo al jefe del hogar que se moviliza, sabiendo que, en muchos de estos casos, no solo es el jefe del hogar quien trabaja, sino también su cónyuge, lo que podría doblar el valor anteriormente mencionado. Esta situación perjudica a varios residentes, porque además tienen que pagar servicios públicos, administración, mercado, etc., con un ingreso que difícilmente alcanza para todos ellos, como bien lo menciona Facundo: "La gente nos decía que estaba pagando alrededor de seis $\mathrm{mil}^{7}$ pesos diarios en transporte ganando el mínimo, entonces esos seis mil pesos diarios representan aproximadamente 280 mil pesos al mes; entonces, si pago transporte, no tengo cómo pagar servicios y, si pago servicios, no tengo cómo hacer mercado, ni pagar cuota de administración..." (entrevista efectuada a uno de los administradores de los conjuntos de Ciudad Verde, 28 de octubre de 2013).

$\mathrm{El}$ ingreso de las familias juega un papel importante a la hora de desplazarse. Es bien conocido que las familias de bajos ingresos tienen, en muchos casos, que gastar más del $25 \%$ de su salario en transporte, lo que genera una disminución en la mo-

Figura 16. Dinero gastado en transporte según situación contractual

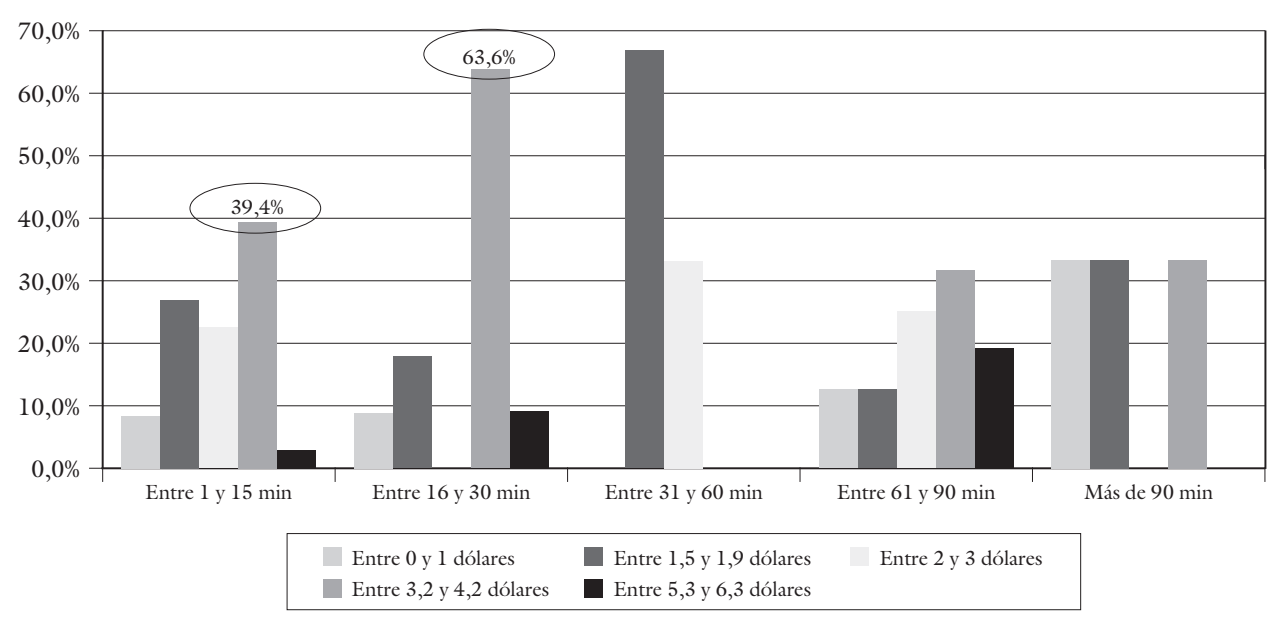

Fuente: elaboración de los autores, construida con base en las encuestas realizadas. 
vilidad individual en algunos sectores de bajos ingresos que gastan un porcentaje importante para transportarse (Bocarejo, 2010), situación que en los últimos años ha llamado la atención de los investigadores, quienes han empezado a relacionar la renta, la movilidad y la exclusión laboral, como un factor que cada vez es más difícil de superar por ciertas familias (Cebollada \& Miralles, 2009). La figura 17 muestra la distribución poblacional según ingreso en

Figura 17. Distribución poblacional según ingreso del hogar

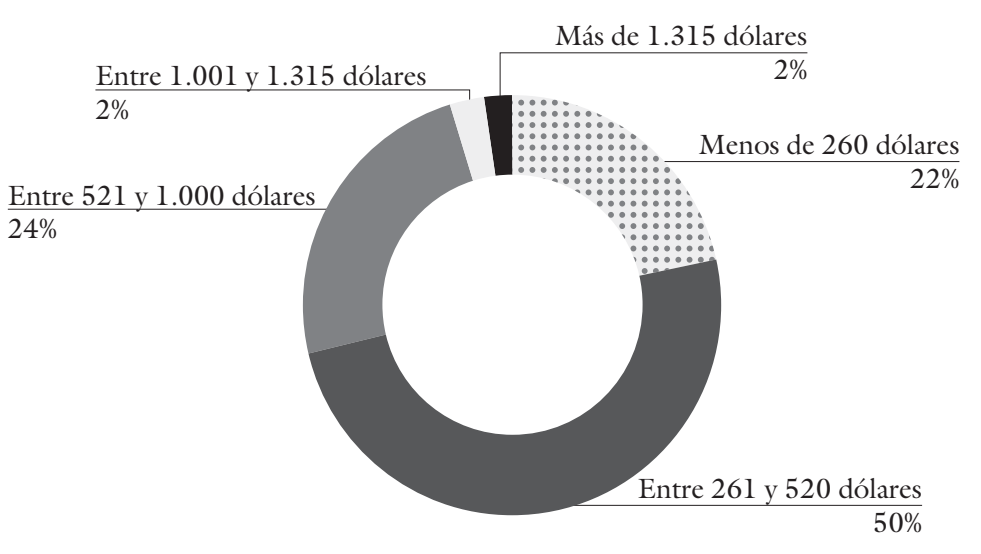

Fuente: elaboración de los autores, construida con base en las encuestas realizadas.

Ciudad Verde.

En Ciudad Verde, se ubican principalmente familias de bajos ingresos, es una ciudadela de viviendas de interés social y prioritario. La figura 18 está desagregada por niveles de ingreso mensual del hogar y el valor que gasta diariamente en transporte el jefe del hogar. Si se calcula el gasto mensual para transporte en el que incurre

\section{territarias 31} el jefe de hogar, estipulado entre 64 y 84 dólares al mes, y lo relacionamos con el nivel de ingreso del hogar, podemos ver que, en los hogares que tienen un ingreso entre 261 y 520 dólares mensuales (que corresponde casi al $50 \%$ de la población encuestada, como se muestra en la figura 17), solo el jefe del hogar estaría gastando entre el 16 y $25 \%$ del ingreso exclusivamente para movilizarse. Si asumimos que el cónyuge también se desplaza e incurre en los mismos gastos de transporte, estaríamos insinuando un gasto entre un $30 \mathrm{y}$ $50 \%$ del ingreso, mucho más del $25 \%$ que menciona Bocarejo.

\section{Conclusiones}

La revisión de lo mencionado permite concluir que la consolidación del área metropolitana de Bogotá y los municipios de la Sabana de Bogotá, en especial Soacha, aún se encuentra en proceso. Además, trabajos como los de Umaña y Rentería (2011), y Alfonso (2001, 2009a) indican que el proceso de metropolización se está llevando a cabo en condiciones de desigualdad por presencia de desequilibrios en el desarrollo de las condiciones sociales, económicas, espaciales y de movilidad entre un ente territorial y los demás, como se observa en los resultados preliminares obtenidos del trabajo de campo realizado por los investigadores.

Acorde con el marco teórico de esta investigación, se analizó el estudio de caso propiciado por el macroproyecto Ciudad Verde, ubicado en el municipio conurbado de Soacha. La razones consideradas para soportar esa decisión involucran el hecho 


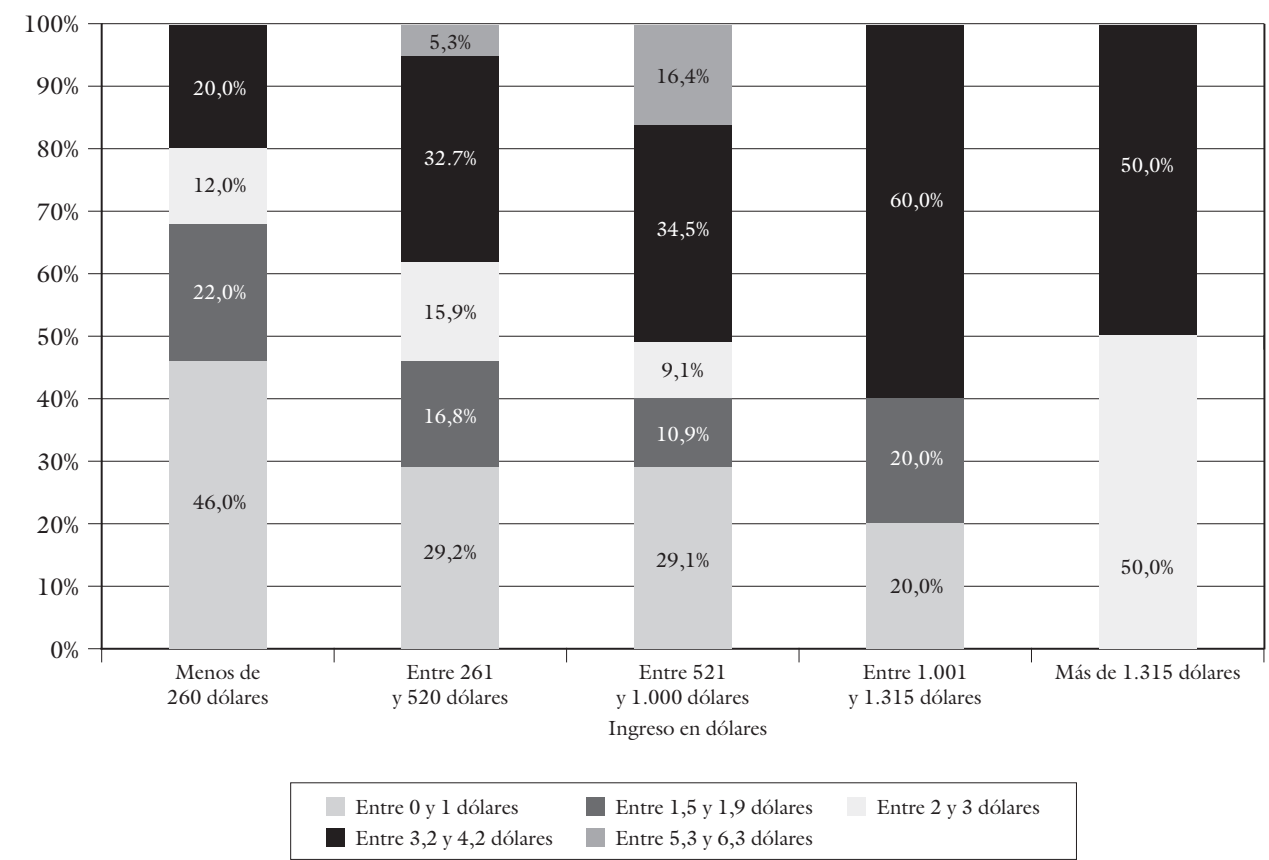

Fuente: elaboración de los autores, construida con base en las encuestas realizadas.

de que este es un municipio monoclasista, especialmente de hogares de ingresos bajos, y también que este nuevo proyecto ha tenido un gran impacto en la comunidad debido principalmente a su nivel de urbanismo, como factor positivo, pero, al mismo tiempo, a su alejada ubicación del gran número de actividades económicas, sociales, educativas, entre otras, que se desarrollan en la capital.

El objetivo principal de esta investigación es mostrar los niveles de segregación a los que pueden estar sujetos los residentes de este macroproyecto, sobre todo desde el punto de vista de los problemas de la movilidad cotidiana que deben afrontar.

De acuerdo con los resultados preliminares, se pudo comprobar que la ubicación del proyecto está realmente apartada de los lugares donde sus residentes realizan las actividades cotidianas. Se observa que más del $50 \%$ de las personas que trabajan se demoran más de 90 minutos en ir a su lugar de trabajo y más de 90 minutos en regresar a su vivienda. Como se ha mencionado a lo largo del documento, esta circunstancia se puede considerar como una causa más de exclusión y de pérdida de tiempo, tiempo 
que podrían destinar para compartir en familia.

Este proceso ha evidenciado que los reclamos más comunes manifestados por los residentes de Ciudad Verde se relacionan con la optimización del transporte y las vías de acceso; por otro lado, tal población reconoce la calidad de las viviendas y del entorno en el cual se encuentra el proyecto, ya que valoran sustancialmente las zonas verdes con las que cuentan, por ejemplo, los parques para los niños. Pero sería de suponer que sucede lo mencionado por Donzelor (1999), citado por Hidalgo (2006), quien explica que existe una integración urbana a través de la materialidad brindada por la urbanización — viviendas conectadas a las redes de agua potable, electricidad, alcantarillado, conectividad vial-, pero, en muchas ocasiones, no hay vinculación efectiva con el resto de la sociedad y, en este caso, del gobierno local (una de las razones por las cuales no cuenta con un mejor sistema de transporte).

Frente al fenómeno de la segregación residencial, se analiza que no solamente se trata de generar vivienda en condiciones dignas para la población residente, sino que también es importante dotar de los bienes públicos necesarios para el efectivo goce del hogar y que se garanticen las condiciones de habitabilidad, accesibilidad y sociabilidad para producir un conjunto armónico y adecuado para el ser humano. Es condición necesaria contar con vías suficientes y en buen estado, complementando con un sistema de transporte eficiente. Así como se piensa en sistemas de transporte inteligentes y orientados al desarrollo, se puede y se debe pensar en sistemas de vivienda orientados al desarrollo y mejoramiento integral de las condiciones de calidad de vida de la población.

Es cierto que el sistema de transporte masivo TransMilenio ha dado los primeros pasos hacia una mejor integración de los barrios periféricos de la capital, llegando a lugares a donde anteriormente no había transporte público, brindando oportunidades que permiten acceder a los bienes y servicios ofrecidos en la gran ciudad a los habitantes de estas zonas, pero desafortunadamente todavía no ha llegado de manera eficiente (rutas alimentadoras) a lugares como Ciudad Verde. Como se pudo comprobar por las encuestas realizadas, la falta de transporte es una de las principales razones que los residentes de 'Narnia' expresan como carente en el proyecto. Es importante darle solución, porque puede acontecer lo que uno de los administradores expresa:

... no cercenan todas estas falencias, créamelo que el enano se les va a crecer, y, más que abandonar, se pueden tomar es acciones; de hecho, qué le digo yo, las soluciones a toda esta problemática que se está evidenciando hasta el momento son manejables, hasta el momento son concertables, pero va a llegar a su momento, porque, hoy día, el ejemplo y la política..., las vías de hecho, entonces sí, efectivamente, va a haber [problemas]... (entrevista realizada a uno de los adminis- 
tradores de los conjuntos de Ciudad Verde, octubre de 2013).

El macroproyecto Ciudad Verde en el municipio de Soacha, en un principio, ha contado con una gran acogida por parte de la población que reside en este lugar; algunos elementos particulares sobre esta percepción positiva se pueden asociar a las zonas verdes disponibles: ciclorrutas, parques, y a las viviendas dignas con todos los servicios básicos. Sin embargo, recientemente, los residentes han empezado a sufrir las consecuencias de una inadecuada y débil planificación en la medida en que no es suficiente construir toda una infraestructura de servicios públicos (energía, agua, alcantarillado, parques y vías), sino, además, es necesario tener acompañamiento por parte del gobierno para dar respuesta a los crecientes problemas y necesidades que se empiezan a vivir en la ciudadela; problemas de educación, salud, seguridad, transporte, entre otros. Situación que seguirá agravándose a medida que lleguen más habitantes si no se toman los correctivos necesarios por parte de las autoridades competentes. Como se mencionó, se espera contar con una población de alrededor de 160.000 habitantes, y si hoy en día, con una población de aproximadamente 25.000 habitantes ya empiezan a florecer estas dificultades, es necesario prever y atender estos escollos.

\section{Referencias}

Alfonso, O. (2001). Metropolización y descentralización: antagonismos y complementariedades. El espacio y la política en el caso de Bogotá y la Sabana. Revista Ópera, 1(1). Recuperado de http://www.redalyc.org/pdf/675 /67510109.pdf

Alfonso, O. (2009a). Metropolítica: un análisis de algunas experiencias metropolitanas globales. Cadernos Metrópole, (21). Recuperado de http://revistas. pucsp.br/index.php/metropole/article/view/5955/4309.

Alfonso, O. (2009b). Profundización de las relaciones de metropolización de Bogotá con la Sabana. Ponencia presentada en el VIII Seminario de Investigación Urbana y Regional Aciur, Universidad Nacional de Colombia, Bogotá. Recuperado de http://institutodeestudiosurbanos. info/dmdocuments/Profundizacion_ relaciones_Metropolizacion_BogotaAlfonso_Oscar-Documento.pdf

Alfonso, O. (2012). Bogotá segmentada. Reconstrucción histórico-social de la estructuración residencial de una metrópoli latinoamericana. Bogotá: Universidad Externado de Colombia.

Arriagada, C., \& Rodríguez J. (2003). Segregación residencial en áreas metropolitanas de América Latina: magnitud, características, evolución e implicaciones de politica. Cepal, Serie Población y Desarrollo.

Avellaneda, P. (2007). Movilidad, pobreza y exclusión. Un estudio de caso en la ciu- territarias 31

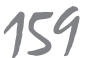


dad de Lima (Tesis doctoral, Universitat Autónoma de Barcelona). Recuperado de http://www.tesisenxarxa. net/TDX/TDX_UAB/TESIS/AVAILABLE/ TDX-1005107-161727//pagldel.pdf De Ávila, A. (2003). Transporte urbano e inclusão social: elementos para politicas públicas. Instituto de Pesquisa Econômica Aplicada, Texto para Discusão No 960.

Bocarejo, J. P. (2010). Transport accessibility and social exclusion: a better way to evaluate public transport investment? Documento presentado en el 12 WCTR, Lisboa, Portugal.

Castells, M. (1972). La cuestión urbana. Madrid: Siglo Veintiuno Editores S.A.

Cebollada, A., \& Miralles, C. (2009). Movilidad cotidiana y sostenibilidad, una interpretación desde la geografía humana. Boletín de la AGE, (50), 193-216.

Cepal. (2012). Panorama social de América Latina. Documento informativo. Santiago de Chile.

Dureau, F., \& Goüeset, V. (2011). Formas de poblamiento y desigualdades en los desplazamientos. La evolución de la movilidad cotidiana en dos periferias populares de Bogotá: Soacha y Madrid (1993-2009). Territorios, (25), 65-93.

Dureau, F., Barbery, O., \& Lulle, T. (2007). Dinámicas metropolitanas de poblamiento y segregación. En F. Dureau, O. Barbary, V. Goüeset, O. Pissoat \& T. Lulle (Coords.), Ciudades y sociedades en mutación. Lecturas cruzadas sobre Colombia (pp. 161-236). Bogotá: Universidad Externado de Colombia.
Dureau, F. (2002). Las nuevas escalas de la segregación en Bogotá. En Metrópolis en movimiento (pp. 162-170). Bogotá: Alfaomega Colombia S.A.

Figueroa, O. (2005). Transporte urbano y globalización. Políticas y efectos en América Latina. EURE, 31(94), 41-53.

Garretón, M. (2011). Desigualdad espacial y utilidad social: esfuerzos de movilidad y accesibilidad en el Gran Santiago. Territorio, (25), 35-64.

Hernández, R., Fernández, C., \& Baptista, P. (2010). Metodología de la investigación. México D.F.: Mc-Graw Hill.

Hernández, D. (2012). Activos y estructuras de oportunidades de movilidad. Una propuesta analítica para el estudio de la accesibilidad por transporte público, el bienestar y la equidad. EURE, 38(115), 117-135.

Hidalgo, R. (2007). ¿Se acabó el suelo en la gran ciudad? Las nuevas periferias metropolitanas de la vivienda social en Santiago de Chile. EURE, 33(98), 57-75. Hurtado, A., Torres, A., \& Miranda, L. (2011). El programa de sistemas integrados de transporte masivo en Colombia: ¿un ejemplo de recentralización de la gestión de las ciudades? Territorios, (25), 95-119.

Jaramillo, S., \& Parias, A. (1995). Vida, pasión y muerte del tranvía en Bogotá. Documento CEDE 95-03. Bogotá: Universidad de los Andes.

Jirón, P., Lange, C., \& Bertrand, M (2012). Exclusión y desigualdad espacial: retrato desde la movilidad cotidiana. Revista INVI, 25(68), 15-57. 
Lizarraga, C. (2012). Expansión metropolitana y movilidad: el caso de Caracas. EURE, 38(113), 99-125.

Lévy, J.-P., \& Brun, J. (2002). De la extensión a la renovación metropolitana: mosaico social y movilidad. En F. Dureau, V. Dupont, E. Lelievré, J.-P. Lévy \& T. Lulle (Coords.), Metrópolis en movimiento. Una comparación internacional (pp. 147-158). Bogotá: Alfaomega.

Lungo, M. (2007). Expansión urbana y la regulación del uso del suelo en América Latina. En M. Smolka \& L. Mullahy (Eds.), Perspectivas urbanas. Temas criticos en politicas de suelo en América Latina (pp. 265-333). Cambridge: Lincoln Institute of Land Policy.

Miralles, C. (2002). Ciudad y transporte. El binomio imperfecto. Barcelona: Ariel Geografía.

Moncayo, A. L. (2011). Enfoques de investigación y organización del trabajo de campo: el estudio de caso y la encuesta. En M. Jimeno, Estrategias metodológicas en la investigación sociojurídica (pp. 65-98). Bogotá: Universidad Externado de Colombia.

Murad, R. (2003). Estudio sobre la distribución espacial de la población en Colombia. Cepal, Población y Desarrollo $\mathrm{N}^{\circ} 48$.

Páramo, P. (2008). La entrevista. En P. Páramo (Comp.), La investigación en ciencias sociales: técnicas de recolección de información (pp. 123-135). Bogotá: Universidad Piloto de Colombia.

Polacchini, A. (1999). Les dépenses pour le logement et pour les transports des me- nages franciliens. Recherche Transport Sécurité, (63), 31-46.

Rubiano, M. (2010). Determinantes endógenos y exógenos de la localización industrial metropolitana: un análisis no paramétrico para el caso de la Sabana de Bogotá. Territorios, (23), 59-100.

Sabatini, F., Cáceres, G., \& Cerda, J. (2007). Segregación residencial en las principales ciudades chilenas: tendencias de las tres últimas décadas y posibles cursos de acción. EURE, 28(82), 21-42.

Salas, A. (2008). Segregación residencial y producción de vivienda en Bogotá, entre imágenes y realidades (Tesis doctoral, Université de Poitiers UFR de Sciences Humaines et Arts, Département de Géographie, Francia).

Social Exclusion Unit (SEU). (2003). Making the connections: final report on transport and social exclusion. London: Office of the Deputy First Ministry.

Umaña, M., \& Rentería, P. (2003). Construcción de escenarios para la planificación de la ciudad-región. El caso Bogotá-Cundinamarca. Cuadernos de Investigación Urbanística, (37), 59-66.

Uribe, J. (2011). La investigación documental y el estado del arte como estrategias de investigación en ciencias sociales. En P. Páramo (Comp.), La investigación en ciencias sociales: estrategias de investigación (pp. 195-210). Bogotá: Universidad Piloto de Colombia.

Weisbrod, G., Ben-Akiva, M., \& Lerman, S. (1980). Tradeoffs in residential location decisions: transportation versus other factors. Transportation Policy and De- territarias 31

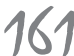




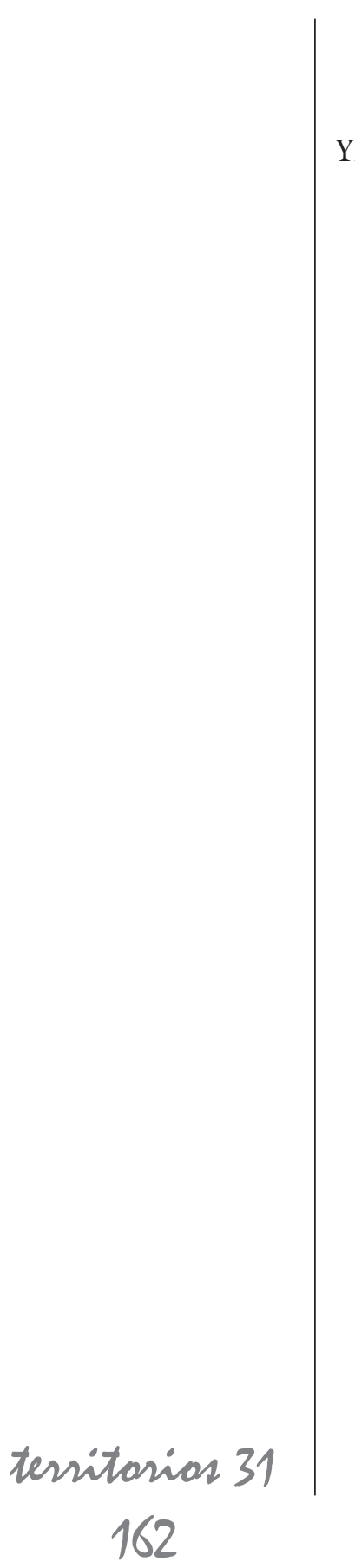

cision-Making, 1(1), 1-14. Recuperado de http://www.edrgroup.com/pdf/ tradeoffs-tpd.pdf

Yin, R. (2009). Case study research. Design and methods ( $4^{\text {th }} \mathrm{ed}$.). Estados Unidos: SAGE Publications.
Normas consultadas

Colombia. Ley 128 de 1994.

Colombia. Ley 1469 de 2011.

Colombia. Ley 1625 de 2013.

Colombia. Resolución 1687 de 2009. 